Ueber neve, otocystenartige Sinnesorgane der Insekten.

Fig. 10. Hinterende derselben 20 mal vergrössert, 8, 9, 10, 11 Ringe derselben. $t r$ laterale Tracheenstämme, $R$ ü Rückengefïss, $X$ das fragliche Organ. $r$ davon nach hinten abgehendes Rohr, $m$ zwei von ihm nach vorne verlaufende Muskeln.

Fig. 11. Das fragliche Organ mit seiner Umgebung. R ü Rückengefäss, tr laterale Tracheenstämme, $\mathrm{f} m$ Flügelmuskel, $\mathrm{X}$ das Organ, m Muskeln, r Rohr, n Nervenstämme, F Fettkörper, C u Cuticula des Integumentes, Ep Epithel desselben. Vergr. 100/1. Zeiss Immers. L.

Fig. 12. Das Organ isolirt. $\mathrm{K}$ Kopf, $\mathrm{Sp}$ Spitze der Blase, Ep Epithel derselben, $\mathrm{C}$ a Chitinkapsel $s_{1}, s_{2}, s_{3}$ die drei Binnensäcke derselben, st gestielte Körper, $m$ Muskeln, $n_{1}$ erster, $n_{2}$ zweiter Nervenstamm, ga ganglienartige Anschwellung des ersten, $\mathbf{r}$ röhrenartige Verlängerung der Blase. Vergr. 400/1. Zeiss Immers. L.

Fig. 13. Ein Paar gestielter Körper, K Körper derselben, st Hohler Stiel, $\mathrm{Cu}$ beschuppte Cuticula, an welche sie angeheftet sind. Vergr. 1000/1. Zeiss Immers L.

N. B. Sämmtliche Figuren nach frischen Präparaten.

Fig. 14. Partie elastischen Bindegewebes aus der Umgebung des fraglichen Organs nach Behandlung mit kochender Kalilauge. Vergr. 1000/1. Zeiss Immers. L.

\title{
Die fibrilläre Structur der Nervenelemente bei Wirbellosen *).
}

Von

Dr. Hans Schultze

in $\mathrm{Kiel}$.

Hierzu Taf. V und VI.

\section{Historisches.}

Während wir in der Neurologie der Wirbelthiere Max Schultze als den Entdecker der ,fibrillären Structur" des Axen-

*) Die hier mitgetheilten Untersuchungen bilden den zweiten Theil der Beantwortung einer Preisfrage, welche die Universität Kiel beä̈glich des 
cylinders betrachten und aus den älteren Angaben Remaks nur die Keime dieser Lehre herauslesen können, so ist die Begriindung der Lehre vom fibrillären Bau bei den Wirbellosen wohl unbestrittenes Verdienst dieses letzteren Forschers.

Remak, der Entdecker des Axencylinders und der marklosen Sympathicusfaser der Wirbclthiere, bereicherte die Neurologie der Evertebraten durch zahlreiche wichtige Entdeckungen und lieferte den ersten sicheren Nachweis der "Primitivfibrille". Man mag es einen merkwürdigen Zufall nennen, dass grade die erste Re mak'sche Beobachtung iiber die Fibrillarität an myelintragenden Fasern von Astacus fluviatilis angestellt wurde. Denn an anderer Stelle ${ }^{1}$ ) habe ich auszufüluren versucht, dass in erster Linie die störenden Lichtbrechungsverhältnisse der Myelinscheide die Ursache waren, dass die Max Schultze'sche Theorie für den Axencylinder der Wirbelthiere keine Anerkennung finden konnte. Indessen darf uns obiger Zufall nicht überraschen, wenn wir die erstaunliche Grösse jener Astacusfasern ins Auge fassen. Ich kann hier die Bemerkung nicht unterlassen, dass verschiedene Classen der Evertebraten unter ibren nervösen Structurelementen iiberraschend klare und insbesondere für den fibrillären Bau instructive Objecte liefern. Diesem Umstande ist es zu danken, dass die Remak'schen Beobachtungen alsbald bei zahlreichen Forschern für verschiedene wirbellose Classen ein lebhaftes Echo fanden, dass grade diese grosse Uebereinstimmung im Bau der Nerven Wirbelloser auf der anderen Seite wiederum Max Schultze in der Vertheidigung seiner Theorie nur bestärken konnte. In Folgendem habe ich kurz die zablreichen neuro-histologischen Arbeiten iiber diesen Gegenstand in chronologischer Reihenfolge gemustert; trotzdem wir in den Arbeiten von

fibrillären Baues der Nerven im Jahre 1877 gestellt hatte. Den ersten Theil habe ich bereits aus äusseren Gründen im Archive für Anatomie und Entwickelungsgeschichte publicirt und verweise ich namentlich Petreffs des Untersuchungsverfahrens auf das dort Gesagte. Der vorliegende zweite Theil, die Nerven der Wirbellosen anlangend, ist inzwischen von mir weiter ausund umgearbeitet worden und habe ich die nöthigen Nachuntersuchungen ebenfalls im anatomischen Institute zu Kiel angestellt. Herrn Professor Flemming sage ich aufs Neue für seine gütigst mir gewährte Unterstützung aufrichtigen Dank!

1) Vgl. meine Abhandlung: „Axencylinder und Ganglienzelle“ im Archiv f. Anat. u. Entwicklungsgeschichte. 1878. Hft. IV. 
Solbrig und Hermann erschöpfende, historische Data finden, hielt ich die nachfolgende Zusammenstellurg für das historische Verständniss der Lehre vom fibrillären Bau nicht für ubberflüssig.

Vor Remak sind in der Literatur nur spärliche bistologische Notizen über feinere nervöse Structurelemente bei Wirbellosen zu finden. Valentin ${ }^{1}$ ) beschreibt einen grauulirten Bau der Nerven sowohl wie der Ganglienzellen von Astacus und Hirudo. Re$\mathrm{mak}^{2}$ ) untersuchte vor Allem das Nerrensystem von Astacus fluviatilis; hier entdeckte er jene breiten, doppelt-contourirten Fasern, wie sie, soweit bis jetzt bekannt, nur noch bei Lumbricus agricola vorkommen. Die breite, durch Osmium sich schwarz färbende Myelinscheide umschliesst das zuerst von Remak gesehene centrale Fibrillenbündel, welehes Remak sofort für das Analogon des Axencylinders erklärte. Remak ${ }^{3}$ ) schildert ferner bei Astacus fluviatilis das Protoplasma der Ganglienzellen als aus zart granulirten, den Kern umkreisenden Fasern bestehend. Remak fügt indess hinzu: "die Fasern erstrecken sich nicht bis in den Fortsatz hinein". Dieselbe "concentrische Streifung" sah Remak") an Ganglienzellen von Raja batis, die längere Zeit in Chromsäure gelegen hatten.

In einer fast gleichzeitig erschienenen Arbeit Hannover $\mathrm{s}^{5}$ ) wird an den Nervenstämmen der Mollusken eine Längsstreifung beschrieben; die Nervenfasern der Krebse dagegen besitzen nach Hannover einen granulirt-nebelartigen Inhalt in membranartiger Huille. Dagegen weicht $\mathrm{Helmboltz}{ }^{6}$ ) in seinen Angaben von Remaks Beobachtung ab. Helmholtz beschreibt die Nerven verschiedener Wirbelloser als zarthäutige Cylinder mit „flussig'em Inhalt“. Helmboltz beschreibt ferner zwischen den "Primitivfäden ${ }^{*}$ aus wellenförmigen Fibrillen zusammengesetztes Zellgewebe, welchem zuweilen Kerne anliegen.

1) Valentin: Nova acta academ. natur. cur. T. XVIII. 1836.

2) Remak: Observat. anat. et microsc. de systemat. nerv. struct. Diss. Berolini 1838.

3) Derselbe in Müller's Archiv 1844.

4) Derselbe: Bericht über die XXIX. Vers. deutscher Naturforscher in Müller's Archiv 1852.

5) Hannover: Recherches mikrosc. sur le système nerv. 1844. Copenhagen.

6) Helmholtz: De fabric. system. nerv. evertebr. Berolini. Diss. 1842. 
Im Jahre 1844 beschreibt $\mathrm{W}^{\mathrm{i}} 1^{1}{ }^{1}$ ) eine „fibrilläre Structur ${ }^{\text {}}$ an den von ihm entdeckten multipolaren Ganglienzellen von Hirudo, und zwar sah Will die Streifung gleich deutlich am Zellkörper wie Fortsatz.

Zwei Jahre später schildern Lebert und Robin²) bei Mollusken feinste Primitivfasern, welche kaum als solche noch erkennbar waren.

Aus dem Jahre 1857 liegen dann zwei weitere Arbeiten von Faivre ${ }^{3}$ ) und $\mathrm{Haeckel}^{4}$ ) vor. Faivre erwähnt membranhaltige Ganglienzellen mit granulirtem Inhalt; die Körnehen schienen in amorpher Masse eingebettet zu. liegen. Auch vergleicht schon Faivre die Primitivfäden der Wirbellosen wegen ihres Aussehens mit den Sympathicusfasern der Wirbelthiere.

Hae ckel erklärt den Inhalt der Primitivfasern von Astae us für eine homogene halbflüssige Masse und hält dieselben für das Analogon des Axencylinders der Wirbelthiere.

Weitere bestätigende Angaben liber eine fibrilläre Structur wurden von Dr. Georg Walter ${ }^{5}$ ) gemacht. Walter beobachtete an den grossen, unipolaręn Ganglienzellen des Gehirns von Lumbricus agricola ein eirenthiimliches Verhalten der Zellfortsätze. Er sah nämlich wie mehrere, von versehiedenen Zellen herstammende Fortsaitze durch innige Verschmelzung zur Bildung eines breiten "Nervenbandes" gewissermaassen zusammenflossen. Gleich häufig sah Walter eine stets dichotonische Theilung der Fortsätze bis in feinste Fibrillen (vergl. seine Fig. Vh auf Taf. II). Der Zellinhalt zeigte stets concentrische Streifung: „Die äussersten Ringe bogen am Ursprung des Fortsatzes von ihrer concentrischen Richtung ab und gingen in den Fortsatz ìber." Walter konnte ferner mit verdünter Salpetersäure und caustischer Natronlauge die Fortsätze wiederholt in "Fibrillen" zerlegen; und zwar giebt er die Maasse der letzteren in der Breite auf durchschnittlich $0,0003 \mathrm{~mm}$ an. Walter beob-

1) Will: ,Vorläufige Mittheilung“ etc. in Müller's Archiv 1841.

2) Müller's Archiv 1846.

3) Etudes sur l'histologie compar. du système nerv. etc. 1857.

4) Haeckel: „Die Gewebe des Flusskrebses". Müller's Archiv 1857.

5) Walter: Mikrosc. Studien ïber d. Centralnervensystem wirbelloser Thiere. Bonn 1863. 
achtete ferner eine multipolare Zelle, deren Körper durch die Präparation in Fibrillen zertrïmmert war. In den Seitennerven von Lumbricus sah Walter an den Fibrillen Varicositäten.

In demselben Jahre 1863 erschien Waldeyers ${ }^{1}$ ) berühmte Arbeit über den $\Delta x e n c y l i n d e r$, in welcher die Lehre vom fibrillären Bau für die Nervenfasern der Wirbellosen allgemein bestätigt wurde; dagegen gelang es Waldeyer bekanntlich nicht, trotz ausserordentlich umfangreicher Versuche mit den verschiedensten Reagentien, den Axencylinder der Wirbelthiere in Fibrillen zu zerlegen. Waldeyer sah zwischen den Fibrillen der Nerven Wirbelloser eine feinkörnige Substanz, welche er indessen nach seinen Präparaten für ein Kunstproduct, fuir zertrïmmerte Fibrillen erklärte. - Waldeyer verdanken wir ferner die erste scharfe Gliederung der Nerven Wirbelloser in zwei Grund-Typen. Der erste Typus entspricht den "nackten" Axencylindern Max Schultze's, wohingegen der zweite Typus der II. Classe der Nervenfasern nach M. Schultze (Sympathicus, Olfactorius) gleichkommt. Auch suchte Waldeyer den Begriff der Nerven-, Faser bei Wirbellosen zu präcisiren, insofern er die Fasern je nach ihrer Breite und Zusammensetzung als "primäre“, "secundïre" ete. Fibrillenbündel zu bezeichnen vorschlägt.

Im Jahre 1864 erschien Leydig. ${ }^{2}$ ) umfassendes Werk tuber den Bau des thierischen Körpers, in welchem zahlreiche wichtige Mittheilungen über das Nervensystem Wirbelloser veröffentlicht wurden. Leydig hat auf die hier erörterten Structurverbältnisse insbesondere die Thoraxknoten mehrerer Insekten, sowie die Ganglien der Hirudineen untersucht.

Von den Ganglienzellen gebraucht er den von ihm zuerst gewählten Ausdruck der concentrischen Streifung des Protoplasmas; die Zellfortsätze erschienen ihm fibrillär. Ueber die Nervenfasern sagt er (pag. 92): „Bei Wirbellosen entstehen die Nervenfasern in den Centren aus der Vereinigang feinster Fäserchen, wobei die Vereinigung nach der Peripherie hin so innig werden kann, dass die daraus hervorgehenden Einheiten ein anscheinend (!) homogenes 1863.

1) Waldeyer: In d. Zeitschrift f. rationelle Medicin. Bd. XX Hft. III.

2) Leydig: Vom Bau des thierischen Körpers. Tübingen 1864. 
Ansehen erhalten." Leydig entdeckte ferner bei Lumbricus doppelt-contourirte Fasern mit "centralem Fibrillenbündel“. Doch war der fibrilläre Bau des letzteren im Verlaufe nicht deutlich zu erkennen; vielmehr zeigte er nur in der Nähe seines Abganges von der unteren Portion des Gehirns ein blassstreifiges Ansehen.

Die Zellfortsätze lïsen sich nach Ley dig in den Centren in „fibrilläre Punktsubstanz" auf. Letztere Bezeichnung wählt er für das centrale „netzförmig-gestrickte Gewirr feinster Fäserchen". Die Nervenfasern enthalten nun nach Leydig entweder nur Punktsubstanz, in Längsziggen angeordnet, oder aber es tritt eine scharfe Differenzirung zu Nerven- Fasern" auf. In dieser Beziehung sind z. B. die Commissuren und peripheren Nerven von Lumbricus nach Leydig schart zu trennen. Nach Leydig sind ferner die cerebrospinalen Fasern von den sympathischen durch ihr Aussehen zu unterscheiden; erstere erscheinen mehr homogen, nicht eigentlich lïngsgestrichelt; letztere dagegen besitzen eine längsgranuläre Strichelung. Die cerebrospinalen haben ferner ein distinctes, bindegewebiges Neurilemm, die sympathischen dagegen besitzen kein Neurilemm.

So traten also zwei der competentesten Forscher riickhaltlos für die "fibrilläre Structur" ein, und doch müssen wir noch eine ganze Reihe entgegengesetzter Angaben späterer Autoren hier citiren. Fast gleichzeitig mit Waldeyer's Arbeit erschienen die sorgfiiltigen Untersuchnngen ron $\mathrm{Buchholz^{1 }}$ ) über das Nervensystem der Siisswassermollusken. Während Buchbolz das Aussehen der Nervenstämme als feinstreifig erkannte, beschreibt er an der Ganglienzelle zwei Substanzen, von denen die eine leicht durch Druck in Form hyaliner Tropfen auspressbar, die zuritckbleibende, körnige Masse aber durchaus gleichwerthig der fibrillär geordneten Inhaltsmasse der Nervenstämme erschien. Die Zellfortsätze dagegen erschienen Buchholz nur selten fibrillär; er schildert sie als breite abgeplattete Bänder. Während nun aber Buchholz die Fibrillen der nervösen Centralsubstanz zwar aus der Theilung der Zellfortsätze hervorgegangen an-

1) Buchholz: Bemerkungen über den histolog. Bau d. Centralnervensystems d. Süsswassermollusken in Müller's Archiv. 1863. 
nimmt, protestirt er ausdrucklich dagegen, diese als Bundel feinster Fibrillen zu betrachten; die "Primitivfasern", die nach $\mathrm{Buchholz}$ einen sehr verschiedenen Breitendurchmesser in ein und demselben Nerven zeigen sollen, und zu denen Buchholz auch die Fortsätze centraler Ganglienzellen rechnet, waren stets "homogen". Dagegen soll die tiber den Oesophagus hinwegziehende obere Commissur bei den von Buchbolz untersuchten Mollusken ${ }^{1}$ ) ein Bündel kaum messbarer Fibrillen repräsentiren. Dieser auffallende Widerspruch in den Ergebnissen seiner Untersuchungen zwingt uns also anzunehmen, dass Buchholz sich die feine Streifung der Nervenstïmme lediglich aus der Zusammensetzung ans "Primitivfasern" erklärt, dieselbe somit nicht auf "fibrillären" Bau im eigentlichsten Sinne zurückfiihrt. Wir vermissen bei Buchholz eben die scharfe Begriffssonderung der "Faser" und "Fibrille".

Schwalbe"), welcher die Ganglienzellen von Limax empiricorum untersuchte, beschreibt an denselben eine concentrische Streifung; die Zellfortsätze strahlen aber pinselförmig in die Zellsubstanz ein.

In einer im Jahre 1869 erschienenen Arbeit Boll's ${ }^{3}$ ) schliesst sich der Verfasser rückhaltlos der Lehre vom fibrillären Bau der Nervenfasern Wirbelloser an, was ich besonders betonen muss, da Boll bekanntlich für den Axencylinder der Wirbelthiere in neuester Zeit diesen Bau nicht anerkennt.

In der im Jahre 1872 veröffentlichten preisgekrönten Arbeit Solbrigs ${ }^{4}$ ) über die Gasteropoden vermisse ich, wie bei $\mathrm{Buch}$ holz, eine scharfe Auseinanderhaltung der Nerven-,Faser" und „Fibrille". Solbrig beschreibt sehr verschieden breite Fasern (bis zu unmessbarer Feinheit!), welche in ihrer Eigenschaft mit der Ganglienzellsubstanz durchaus übereinstimmen, insofern beide aus "fest-weicher" homogener Masse bestehen. Fibrillären Bau sah Solbrig nur bei Anwendung von Osmiumsiure und

1) Limnaeus stagnalis; Planorbis corneus.

2) Schwalbe: Ueber den Bau der Spinalganglien etc. in M. Schultze's Archiv IV. 1868 .

3) Boll: Beiträge zur vergl. Histologie d. Mollusken-Typus. Schultze's Archiv Bd. IV. 1869.

4) Solbrig: Ueber die feinere Structur der Nervenelemente bei den Gasteropoden. Von d. medic. Facultät zu München 1870 gekrönte Preisschrift. 
Chromsäure und hält denselben für den Ausdruck einer Unregelmässigkeit an der Oberfläche der Fasern (!). Solbrig sagt pag. 42: „Die fibrilläre Anschaung hat viel Verlockendes für sich, da im Ganglion aus der fein-faserigen Substanz breite Fasern hervorgehen. Es ist wahrscheinlich, dass die breiten Fasern aus einer Summe feiner Elemente bestehen, aber es ist möglich (!), dass die Vereinigung gleich ist einer Verschmelzung etc."

Die neuesten Beiträge zur Kenntniss des Nervensystems Wirbelloser liefert Hermann ${ }^{1}$ ) in seiner ausgezeichneten Monographie über den Blutegel. Was die hier discutirten Structurverhältnisse betrifft, so constatirte Hermann in den peripheren Nerven von Hirudo medic. überall die Fibrille als letzte Structureinheit. Dagegen beschreibt Hermann ein von den Angaben frïherer Autoren ganz abweichendes Verhalten der Ganglienzellsubstanz bei Hirudo; der Zellinhalt erschien im frischen Zustande ungemein hell und bestand in Innern aus verschieden grossen Körnchen; die Rindenschicht der Zelle hingregen war glashell, homogeh, desgleichen der Zellfortsatz, an welchem Hermann durchaus keine weitere Structur erkennen konnte. Indessen wurde die Untersuchung im frischen Zustande erheblich erschwert durch ein körnig-fibrilläres, der Zelle aussen anhaftendes Gewebe, sodass Hermann seine Zuflucht zu erhärteten Alcoholpraparaten nehmen musste. An diesen nun sah Hermann einen ganz ähnlichen Ban, wie ihn Fleischl ${ }^{2}$ ) an den mit Borsäure behaudelten Zellen des Ganglion Gasseri von Rana beschrieben (globuläre und interglobuläre Substanz). Nach Hermann war die den grösseren Theil der Zelle erfüllende Substanz homogen oder feinkörnig; sie giebt der Zelle Form und Gestalt und constituirt allein den Fortsatz; dieser letztere zerfällt an einigen Zellen in zwei, an anderen in drei "Fibrillen". deren Breitendurchmesser Hermann auf $0,006 \mathrm{~mm}$ angiebt. Das uns hier hauptsächlich interessirende Hauptverdienst der Hermann'schen Arbeit liegt in der klaren Definition des Begriffs der

1) Hermann: Centralnervensystem v. Hirudo medic. Gekrönte Preisschrift. München 1875.

2) Fleischl: „Ueber die Wirkung von Borsäure auf frische Ganglienzellen". Wiener Sitzungsberichte Bd. XLI. II. 1870. 
"Nervenfaser". Nach Hermann verlaufen in dem durch Neurilemmascheidewände abgefächerten Nervenstamm „nackte" Fibrillenbüdel. Das primäre Neurilemmarohr ist nämlich in nahezu gleichgrosse Fächer abgetheilt, der Inhalt dieser Fächer repräsentirt somit eineder Nervenfaser der Wirbelthiere durchaus analoge Einheit.

Werfen wir einen Blick zurtick auf die zahlreichen Untersuchungen genannter Autoren, so leuchtet es ein, dass die auf Remak zurückzuführende Lehre vom fibrillären Bau der Nerven Wirbelloser eine erweiternde Bestïtigung gefunden hat durch die Studien von Hannover, Will, Lebert und Robin, Walter, Waldeyer, Leydig, Boll und Hermann. Von diesen Forschern sind es Walter, Waldeyer und Leydig, welche der Lehre die allgemeinste Ausdehnung verschafft und sich den grössten Ruhm ibrer Begrilndung erworben haben. Andere Autoren wie $\mathrm{Buch}$ holz, Solbrig halten zwar an der Thatsache fest, dass in den gangliösen Centren aus der fortgesetzten Theilung der Zellfortsätze die körnig-fibrilläre Centralsubstanz hervorgeht, dass ferner in dieser Substanz die Bildungsstätte der aus dem Ganglion entspringenden Nerven zu suchen ist; indessen halten sie es für nicht erwiesen, dass Zellfortsätze und Nervenfasern und -Stämme als Bündel von Fibrillen zu betrachten seien.

Während die Ansicht von Helmholtz, dass der Inhalt der Nervenstämme im Leben "fliussig“" sei, keine Beachtung bei den späteren Autoren gefunden, treten $\mathrm{Haeckel}, \mathrm{Buchholz}$ und Solbrig für eine ,homogene" Beschaffenheit der Zellfortsätze und Nervenfasern ein. Wir sehen also, es sind genau dieselben Controversen, welche wir gelegentlich einer Erörterung der Max Schultze'schen Theorie ${ }^{1}$ ) zu erwähnen hatten. Dieselben Argumente (Auflösung der Zellfortsätze in fibrilläre Centralsubstanz, Aufbau der Nervenfasern aus dieser letzteren) sind es, welche auch hier einer in der Continuität der Nervenfasern und Nervenstämme beobachteten Fibrillarität mächtig das Wort reden. Nur vermissen wir, und zwar gerade bei den neueren Autoren, ein Argument, welches Max Schultze mit so viel Glück furr seine Theorie heranzog; ich meine das Verhalten der Nervenfasern an der

1) Vgl. meine Darstellung im Archiv für Anatomie u. Entwickelungsgeschichte. Heft. IV. 1878. 
Peripherie, ihre Aufsplitterung in "Fibrillen", wie wir sie aus so vielen Terminalgeweben bei Wirbelthieren kennen. Der einzige Autor, der meines Wissens das Verhalten der Nervenfasern Wirbelloser an der Peripherie erforschte, ist Flemming ${ }^{1}$ ). Flemming beschreibt Nervenendigungen im Epithel des Fiblerknopfs von Helix pomatia sowie im Epithel der Mantelzacken von Mytilus edulis. Da Flemming auch in dem Endplexus der Nerven genannter Gegenden bis dahin völlig unbekannte Structurverbältnisse entdeckte, werde ich weiter unten eingehender darauf zuriickkommen.

\section{Gasteropoden.}

Die von mir untersuchten Gasteropoden Helix pomatia, Helix nemorosa und Arion ater zeigen hinsichtlich der feineren Structurverhältnisse des Nervensystems eine derartige Uebereinstimmung, dass die nachfolgende Schilderung für alle 3 Thiere gleichmüssige Geltung besitzt.

\section{Untersuchungsmethoden.}

Ich untersuchte von Helix pomatia, Helix nemorosa und Arion ater das Ganglion supra- und infraoesophageum, sowie die peripheren Nervenstämme und die Commissuren, ferner prüfte ich die (sympathischen) Darmnerven der genannten Gasteropoden; von Helix pomatia untersuchte ich ausserdem den Fühlernerv mit dem Ganglion, den peripherischen gangliösen Strängen sowie die Nervenendigungen im Epithel des Fuhlerknopfs. Meine Untersuchungen wurden sowohl an frischen wie an conservirten Objecten angestellt. Zar Untersuchung im frischen Zustande wählte ich das Jodseru m sowie vorzugsweise die zähe Leibesflüssigkeit dieser Thiere, welche auch im lebenden Körper die Ganglien und grösseren Ner-

1) Flemming: „Die haaretragenden Sinneszellen in der Oberhaut der Mollusken"; sowie Derselbe: „Untersuchungen über Sinnesepithelien der Mollusken“; M. Schultze's Archiv Bd. V u. VI. 1870. Derselbe: „Zur Anatomie der Landschneckenfühler u. zur Neurologie d. Mollasken." Zeitschrift f. wissensch. Zoologie Bd. XXII, Heft III. 
venstämme umspült. Freilich musste ich mir sagen, dass die letztere nur bedingungsweise als ,indifferent" betrachtet werden kann, da eine Verunreinigung durch beigemengten Hautschleim kaum zu vermeiden ist. Ausserdem prüfte ich Schnittpräparate frisch gefrorener Objecte. Von conservirenden Reagentien benutzte ich ausschliesslich die gelegentlich meiner Untersuchungen uber den Axencylinder erprobten Reagentien, und zwar vorzugsweise sehr stark verdünnte $(-0,02$ pCt. herab) Lösungen des Ammonium bichromicum, schwache Osmiumsäurelösungen und den von $\mathrm{R}$ a $\mathrm{n}$ vier empfohlenen Alcohol dilutus $(20-10 \%)$. - Zur Erlangung gunstiger Schnittpräparate härtete ich die herauspräparirten Ganglien sowie ganze Thiere in Alcohol; auch härtete ich vorher gefrorene Objecte in 1-2procentiger Osmiumsäure. Zur Beobachtung der Darmnerven habe ich mit gutem Erfolge die Gold-Ameisensäure-Methode benutzt; auch lieferte mir concentrirte Essigsäure mit nachheriger Carmintinction vortreffliche Structurbilder der Darmnerven. Von Tinctionsmitteln kann ich das carminsaure Ammoniak, das picrocarminsaure Natron, Haematoxylin hervorheben.

\section{Die Ganglienzelle der Gasteropoden.}

Zerzupft man ein Ganglion supra- oder infraoesophageum eines Gasteropoden und betrachtet man das Präparat mit schwachem System, so wird das Auge iberrascht durch die auffallende Differenz in der Grösse der Ganglienzellen. Schon Leydig hebt diese ïberraschenden Grössenunterschiede hervor. Buchholz beschreibt in seiner oben citirten Arbeit Zellen, deren grösster Durch. messer $240 \mu$ betrug, wohingegen kleinste, noch mit allen Attributen centraler Ganglienzellen versehene Zellkörpcr nur noch $3 \mu$ maassen. Solbrig hildet eine Zelle $a b$, deren Längsdurchmesser $220 \mu$, deren Querdurchmesser $150 \mu$ massen. Der grösste von mir bestimmte Diameter (spindelförmige Zellen schloss ich aus) betrug $320 \mu$; der kreisrunde Kern dieser riesigen Zelle maass $260 \mu$ im Durchmesser.

An frisch zerzupften Objecten gelang es nur selten, wie dies auch Solbrig hervorhebt, scharf abgegrenzte Zellkörper zu sehen; denn es haftete den Zellen aussen immer eine Summe feinster Reiser, die ich für körnig-fibrilläre Centralsubstanz halte, an. Zur 
gaten Isolirung der Zellen bediente ich, mich, wie Solbrig dies mit Recht empfiehlt, einer ganz schwachen Lösung eines Chromsalzes. Solbrig rühmt bei dieser Gelegenheit den Vortheil der Kalisalze das Bindegewebe zu maceriren. Ohne dieser ganz allgemein aufgestellten Bchauptung widersprechen $\mathrm{zu}$ wollen, will ich hierzu nur bemerken, dass ich mit dem Ammonsalz der Chromsäure ganz vortrefflich isolirte Zellen erhalten habe, dass ich ferner die der im frischen Zustande zerzupften Zelle anhaftende Substanz nicht wie Solbrig für Bindegewebe sondern wie schon gesagt, für nervöse Fibrillen halten muss. Die centralen Ganglienzellen der Gasteropoden, vor Allem die an der Peripherie der Ganglien gelegenen riesigen unipolaren Zellen liegen in den Maschen eines bindegewebigen Fachwerks und senden ihre Fortsätze in die im Centrum des Ganglion befindliche körnig-fibrillïre Substanz, welch' letztere im frischen Ganglion nur schwer von ihrer bindegewebigen Umgebung sich isoliren liisst; dagegen fallen beim Zerzupfen eines gehärteten oder nur in schwacher Chromsalzlösung macerirten Ganglion leicht die Ganglienzellen wie auch die nervöse Centralsubstanz aus den Maschenräumen des bindegewebigen Netzwerks heraus.

Solbrig hat nun ferner, trotzdem er mit 0,03procentiger Chromkalilösung arbeitete, immer nur geschrumpfte Zellen mit diesem Reagens erhalten. Dem gegenüber muss ich bemerken, dass mir eine 0,05-0,02procentige Lösung des Ammonium bichromicum vortrefflich erhaltene Zellen lieferte; ich habe schon bei anderer Gelegenheit den Vortheil des Ammonsalzes, nicht nachschrumpfend zu wirken, erwähnt, und demgemäss auch bei lïngerer Einwirkungsdauer dieses Reagens immer zufriedenstellende Bilder erhalten. Ich habe die Reagentien stets durch die Untersuchung im frischen Zustande controllirt und will daher zunächst eine so beschaffene Zelle schildern.

An einem ganz frischen, im Blute oder der Leibestlissigkeit zerzupften Präparate oder an Schnitten durch frisch gefrorene Objecte sah ich in der Regel eine „concentrische Streifung"; an der Abgangszelle des Fortsatzes bogen Fibrillen in diesen uber. Bei grösseren Zellen muss man, um dies sehen zu können, selbstverständlich scharf auf den Fortsatz einstellen; in der Mehrzahl der Fälle zeigte der Fortsatz auch in der Continuität fibrilläre Längszeichnung. Neben den Fibrillen war im frischen Zustande 
und an Gefrierschnitten keine weitere Substanz zu erkennen; nur imponirten die Zwischenräume der Fibrillen als helle Streifen. An conservirten Präparaten hingegen sah ich oft deutlich neben, resp. zwischen den Fibrillen eine körnige Substanz. Manche Zellen nun liessen im frischen Zustande die Fibrillen nicht so scharf erkennen, zeichneten sich dafür durch ein eigenthümlich glasiges oder gallertiges Aussehen aus. Setzte ich nun einem solchen Präparate einen Tropfen 0,05procentiger Osmiumsäure zu, so ward die Streifung alsbald deutlicher. Bei häufiger Wiederholung dieses Versuches gewann ich die Ueberzeugung, es möchten in der zuvor glasig-zähflüssig erschienenen Substanz vielleicht veränderte Lichtbrechungsverhältnisse eingetreten sein, welche die Erkennung der Fibrillen begünstigten. Der Umstand, dass ich an conservirten Präparaten die Streifung ohne Ausnahme, an frischen Zellen dagegen nicht immer gleich scharf gesehen, bringt mich auf die Vermuthung, es könnten die interfibrillären Körner infolge der Einwirkung der Reagentien durch Gerinnung aus jener glasigen zähflüssigen Substanz entstanden sein. Diese körnige Substanz kann je nach der Einwirkung des Reagens verschieden stark zu Tage treten; wandte ich stärkere Concentrationsgrade des Chromsalzes oder der Osmiumsäure an, so erschienen die Zellen häufig ganz granulirt, von Fibrillen war nichts zu erkennen. Ich hebe dies hervor, weil Solbrig behauptet, die Streifung trete mit zunehmender Concentration der Osmiumsäure deutlicher hervor. Ich sah dieselbe, wie gesagt, am schärfsten an ganz frischen Zellen und bei der Anwendung stark verdünnter Chromammoniumlösung. Ausser diesen rom Zufall der Reagenswirkung abhängigen Unterschieden kann ich die Möglichkeit nicht von der Hand weisen, dass die körnig geronnene Substanz in verschiedenen Zellen verschieden stark vertheilt sein mag und auch so die Erkennung der Fibrillen modificirt.

Diesen fibrillären Bau nun sah ich nicht nur an den centralen Zellen, sondern ebenfalls an den in erstaunlicher Fülle die Verzweigungen der Darmnerven begleitenden Ganglienzellen.

Von jeher ist die Frage nach der Polarität der Ganglienzellen Wirbelloser von allen Untersuchern lebhaft discutirt worden. Was in specie die Zellen der Gasteropoden betrifft, so macht schon Buchholz die, wie mir scheint, treffende Bemerkung, „dass der unipolare Habitus der grossen Zellen sich aus ihrer 
Lage im Ganglion erkläre, indem nur nach dem Centrum des Ganglion hin Fortsätze auszusenden seien." Diese zwar etwas teleologische Deutung erklärt vollkommen den unipolaren Habitus jener grossen Zellen aus der Randzone der Ganglien. Nach meinen Beobachtungen ist der letztere aber für die centralen Ganglienzellen Wirbelloser ïberhaupt der vorwiegende. Auch möchte ich entgegen Leydig den Ausdruck „unipolar" für diese den Wirbellosen durchaus characteristischen Gebilde aufrecht halten. Leydig sah nämlich im Gehirn von Lymnaeus stagnalis wiederholt diesen einen Fortsatz sich zuletzt auflösen in ein wahres Geflecht feiner Fasern und steht Leydig auf Grund dieser Thatsache nicht an, jene unipolaren Zellen strahligen, multipolaren Ganglienkugeln gleichzusetzen. Nach dem gewöhnlichen Sprachgebrauch soll man aber doch nur dann von "selbstständigen" Fortsätzen reden, wenn dieselben isolirt aus dem Zellleib entspringen. Apolare Zellen habe ich nicht constatiren können; überall, wenn ich zweifelte, war die Möglichkeit nicht ausgeschlossen, ein kleiner Zellstumpf, der etwa an einer dem Auge abgewendeten Seite der Zelle entspringe, könne dem Blicke durch den oft riesigen Zellleib entzogen bleiben. Aehnlich äussern sich Walter, Buchholz und Solbrig tiber das Vorkommen apolarer Zellen.

Bipolare Zellen im gewöhnlichen Sinne, d. h. wo von zwei entgegengesetzten Polen Fortsätze abgehen, habe ich unter den grösseren Zellen aus der Peripherie der Ganglien nicht gesehen; indessen zeigten diese grossen Zellen häufig ein Verhalten, wie es Fig. 1 Taf. V zeigt: es entsprangen von ein und demselben Pole zwei und oft mehr Fortsätze. Die bipolare Form ist dagegen die gewöhnliche für die kleineren mehr nach dem Centrum des Ganglions hin gelagerten; auch ist die grosse Mehrzahl der von mir in fast allen peripherischen Nervenstämmen und -Fasern gesehenen sogenannten "interponirten“ Ganglienzellen bipolar. Auf die Bedeutung dieser letzteren werde ich weiter unten noch zu sprechen kommen.

Grosse multipolare Zellen habe ich in den Central-Ganglien bei Gasteropoden nur sehr selten angetroffen; es ist vielleicht ein Zufall, dass sie mir in den wenigen Fällen bei Arion ater relativ häufiger zu Gesichte gekommen sind. Dagegen sah ich bei Helix pomatia in den Ganglienstrata des Fühlerknopfs sehr häufig multipolare Zellen; am häufigsten jedoch begegnete mir die multi- 
polare Form in den Verzweigungen der Darmnerven bei allen drei von mir untersuchten Gasteropoden. Ich halte die multipolare Form der sympathischen Ganglienzelle der Gasteropoden durchaus für die Regel, and will ich gleich bemerken, dass dies die einzige Differenz ist, welche ich im Baue der sympathischen und centralen Ganglienzelle statuiren konnte.

Solbrig beobachtete an bipolaren Zellen häufig ein verschiedenes Verhalten beider Fortsätze; während der eine, wie gewöhnlich, granulirt war, erschien der andere völlig homogen und endete dann in der Regel mit knopfförmiger Anschwellung im Kernkörper. (Vgl. Solbrigs Figuren 17, 25 auf Taf. II und Fig. 12 auf Taf. IV.) Zunächst möchte ich solche Zellen, deren einer Fortsatz im Kernkörper endet, nicht in die Reihe der gewöhnlichen bipolaren Zellen rechnen. Auf die höchst auffallenden Kernkörperfortsätze komme ich weiter unten zurück, wo anch die Frage nach den Kernfortsätzen erörtert werden wird. Beides sind so auffallende Bildungen, dass sie wohl einer gesonderten Betrachtung werth sind. An den gewöhnlichen bipolaren Zellen habe ich nie einen solchen Unterschied in dem Verhalten der Fortsätze wahrnehmen können, trotzdem ich eine grosse Anzahl bipolarer Zellen eigens darauf geprüft habe.

Der Fortsatz der grossen unipolaren Zellen entspringt, wie dies auch Solbrig hervorhebt, in der Regel mit breiter Basis und pflegt im weiteren Verlaufe etwas schmaler zu werden; häufig setzte sich das Pigment der Zelle eine Strecke weit in den Fortsatz hinein fort, und bin ich geneigt diesem letzteren Umstande die Ursache der Caliberschwankung beizumessen, insofern das im Innern zwischen den Fibrillen gelagerte Pigment eine mehr lockere Fügung der letzteren bedingt. In ganz ähnlicher Weise hat ja auch beim sogen. Axencylinderfortsatz der Wirbelthiere die Abnahme der in der Nähe der Zelle noch reichlicher vorhandenen körnig-interfibrillären Substanz ein Schmalerwerden des Fortsatzes zur Folge.

Die von Solbrig gezeichneten spitz auslaufenden und schliesslich zur isolirten Fibrille (!) werdenden Fortsätze muss ich nach eingehender Prüfung für Artefacte, durch schrumpfende Reagentien bedingt, erklären. Solbrig hält die Zellfortsätze im Allgemeinen für breite, abgeplattete Bänder (pag. 33) und schliesst dies aus häufig an ihnen beobachteter Faltenbildung. An frischen und con- 
servirten, ihrer Form und Gestalt nach wohlerhaltenen Zellen zeigten die Fortsätze sich stets cylindrisch; freilich zeigten Querschnittsbilder nicht immer eine kreisrunde Form; indessen möchte ich deshalb die Bezeichnung Cylinder nicht ersetzt sehen durch das zweideutige "Band“. An so grossen Zellkörpern ist uberdies in Zupfpräparaten kaum eine Compression von Seiten des Deckglases zu vermeiden, die sich denn auch häufig genug neben abgeplatteten Fortsätzen durch Faltungen der Kernmembran etc. manifestirte. Varicositäten habe ich an centralen Ganglienzellfortsätzen mit keinem der von mir benutzten Reagentien gesehen.

Wiederholt aber gelang es mir in Fibrillen aufgesplitterte Zellfortsätze zu beobachten. In Figur 2 sieht man an der Rissstelle zwischen den Fibrillen eine körnige Substanz; ausserdem ist der Fortsatz durch den Besitz einer scharf contourirten bei a in der Figur sich abhebenden Membran ausgezeichnet.

In ihrem weiteren Verlauf nun tritt in der Regel mehr weniger weit von der Zelle eine Theilung der Fortsätze ein; Regel ist die dichotomische Verïstelung; die Aeste waren immer gleich fibrillär wie der Stamm. An den grossen unipolaren Zellen sah ich sehr häufig die von Buchholz treffend als "handschuhfingerartig. bezeichnete Theilungsform; die Summe der Theiläste übertraf, im Querschnitt gemessen, bei Weitem den Stammfortsatz.

Ich gehe nunmehr zur Besprechung der Kerne der Ganglienzellen ïber. Die Grössenverhältnisse derselben berührte ich schon oben. Die normale Form des Kerns ist die kugelrunde; ich sah wiederholt die zuerst von Buchholz beschriebene "Nierenform", muss es aber unentschieden lassen, ob diese Form nicht etwa die Folge eines Zupfinsultes gewesen. Meine Figur 3 illustrirt eine zuerst von Solbrig (vgl. l. c. Fig. 23 auf Taf. II) gezeichnete Eigenthümlichkeit. In der Gegend des im Profil gezeichneten Kern-,Hilus" einer solchen nierenförmigen Zelle sieht man nämlich eine lichte Stelle, und ich zweifle keinen Augenblick, dass diese Erscheinung nicht etwa mit anderen von mir später zu beschreibenden Bildern die Existenz einer Kernmembran beweisen kann. Es hatte sich hier nicht etwa der Kerninhalt von seiner Membran zurückgezogen. Vielmehr halte ich den lichten Hof für das optische Bild des in der Zellsubstanz zur Aufnahme des Kernes befindlichen kugeligen Hohlraumes. Allerdings bätte ja die Zupfnadel diese Einkerbung des Kernes bewirken können; 
indessen vermisste ich an der correspondirenden Stelle des Zellkörpers jegliche Spur einer Läsion.

Was nun die feinere Structur des Kernes betrifft, so erschien derselbe an frischen Zupfpräparaten sehr fein granulirt und zeigte im Innern e in grösseres Kernkörperchen mit meist excentrischer Vacuole. An Gefrierschnitten dagegen erschienen die Kerne während der ersten Secunden der Beobachtung als helle, homogene Blasen inmitten der sie umgebenden feinstreifigen Zellsubstanz. Bei längerer aufmerksamer Beobachtung aber sah ich ein feines Netzwerk; die Netzbalken waren durch aneinandergereihte Körnchen gebildet; indessen boten nicht alle Kerne dasselbe in gleich ausgesprochener Weise dar, und ich gewann den Eindruck, dass mit dem weiteren Aufthauen des Schnittes das Kernreticulum deutlicher und dichter wurde. Diese Differenzen sowie der Umstand, dass nicht jeder Kern ein Kernkörperchen zeigte, mögen ja darin zum Theil ihren Grund haben, dass der Schnitt immer ungleich dicke Kernabschnitte getroffen hatte. An conservirten Präparaten war das Aussehen der Kerne ebenfalls verschieden, je nach der Wahl des Reagens- und Tinctionsmittels. Mit Osmiumsäure und Haematoxylin erhielt ich bald fein, bald grob reticulirte Kernbilder. Chromsalze, carminsaures Ammoniak, Alcohol lieferten stets verschieden feinkörnig granulirte Kerne. Ich habe mich darauf beschränkt hier zu beschreiben, was ich an den Kernen mit den genannten Methoden wahrnahm und unterlasse es, daraus Schlutsse auf die Beschaffenheit des Kerns im Allgemeinen zu ziehen, da diese Objecte offenbar zu ungünstig sind um im sicher lebenstreuen $\mathrm{Zu}$ stand beobachtet zu werden. Es lässt sich nicht bestimmen wie viel Veränderungen auf Rechnung des Gefrierens, auf das Anschneiden der Zellen, auf die Zusatzflïssigkeit und die Reagentien zu setzen sind.

Ich will nunmehr die Frage nach den Kernfortsätzen und Kernkörperfäden erörtern. Dieselben sind für Wirbellose wohl zuerst von G. Wagener ${ }^{1}$ ) beschrieben worden, und zwar beobachtete Wagener diese Bildungen an Ganglienzellen von Hirudo, Limax ater und Lymnaeus stagnalis. Aebnliche Beobach-

1) G. Wagener: Ueber den Zusammenhang des Kernes und Kernkörpers der Ganglienzellen mit dem Nervenfaden. Zeitschr. f. wiss. Zoologie Bd. VIII 1858. 
tungen sind von Arnold und Lieberkühn bekanntlich bei Wirbelthieren angestellt, während Arnold ${ }^{1}$ ) und Owsjannikow ${ }^{2}$ ) Kernkörperfortsätze auch bei Wirbellosen beschrieben haben. Le ydig hat nie weder Kernfortsätze noch Kernkörperfäden gesehen. In neuerer Zeit sind die letzteren wieder von Solbrig bei Gasteropoden beobachtet.

Ich will zunächst bemerken, dass ich bei den von mir untersuchten Wirbellosen niemals im Kernkörper endende Fasern gesehen habe. Dagegen beobachtete ich bei Gasteropoden eine Reihe von Fällen, welche zur Bestätigung der Kernfortsätze dienen können. Ich habe in den Bildern 3, 4, 5, 6, 7, diese Fälle zusammengestellt. Die in den Figuren 3 u. 4 abgebildeten Fortsätze kann ich nicht als Kunstproducte gelten lassen, wie ich solche in den Figuren 5 und 7 zum Vergleich daneben gezeichnet habe. Die oft beträchtliche Länge (Fig. 3) dieser mit dem Kerne die gleiche lebhafte Carmintinetion zeigenden Fortsätze, die völlige Integrität des Kernleibes und seiner Membran bürgen mir für eine normale Erscheinung. Ausser durch seine lebhafte Carminfärbung zeichnet sich der im Kern endende Fortsatz stets durch sein grob granulirtes Aussehen aus, während der andere Proto pla s ma fortsatz fein-fibrillär erschien. Dagegen weisen die Figuren 5, 7 darauf hin, dass es sich in diesen Fällen um Kunstproducte, durch Zupfinsulte herbeigefïhrt, handelte. Hier war nämlich der Kerninhalt stets nach der Ausstillpungsstelle der Kernmembran hingezogen; häufig floss der Kerninhalt gewissermaassen durch die kurzen buckelförmigen Fortsätze aus; die weiss gezeichneten Theile des Kernes stellen eben Hohlräume innerhalb der Kernmembran dar.

Die bei Gasteropoden in äusserst wechselnder Anzahl vorkommenden Kernkörperchen zeigen im frischen Zastande scharfe Contoure und in der Regel eine meist etwas excentrisch gelegene Vacuole; in conservirten Präparaten sah ich häufig bis zu fünf solcher Vacuolen. Die Grösse des Kernkörperchens steht in Relation zur Grösse des Kernes. Buchholz giebt an, dass seine Grösse bis zu einer gewissen Grenze progressiv

1) Arnold: Ueber d. fein. histolog. Verh. d. Ganglienz. d. Sympath. d. Frosch. Virchow's Archiv. Bd. XXXII. 1865.

2) Owsjannikow: Annales des sciences natur. de St. Petersbourg. zoolog. Tome XV 1862. 
der Grösse des Kernes proportional sei; jenseits dieser Grenze sollen dann zahlreiche Körperchen im Kern auftreten. Ich zählte auch in kleineren Zellen und somit kleineren Kernen, wiederbolt mehrere Kernkörperchen: doch sah ich an ganz frischen Präparaten sowie an Gefrierschnitten immer nur ein grösseres durch scharfe Contoure ausgezeichnetes Körperchen. Leydig beobachtete bei Lymnaeus stagnalis bis zu 8, Solbrig bei Helix pomatia bis zu 13 Kernkörperchen in demselben Kern. An gehärteten Chromsalzpräparaten habe ich nicht selten noch mehr solide Körperchen gezählt, unter denen aber immer eins wiederum sich durch seine Grösse auszeichnet.

Die contralen Ganglienzellen der Gasteropoden sind ausgezeichnet durch eine eigenthümlich circumserip te Localisirang von Pigmentkörnern. Schon Leydig hebt in seinem elassischen Werke "Ueber deä Bau des thierischen Körpers" hervor, dass die Ablagerung von Pigment in den Ganglienzellen Wirbelloser doppelter Art sei; einmal tritt das Pigment in Gestalt von Körnern auf, welche in die Zellsubstanz eingestreut liegen, ganz wie es bei Wirbelthieren die Regel ist. Dies ist nach meiner Beobachtung der Fall bei den centralen Ganglienzellen der Gasteropoden und Muscheln. Bei anderen Wirbellosen begegnen wir nach Leydig einer mehr diffusen Pigmentirung der Zellkörper, wo eine gelb oder roth gefärbte Flïssigkeit die Ganglienkugeln durchtränkt. Leydig sah dieses Verhalten bei Paludina.

Was nun speciell das Pigment bei den Gasteropoden betrifft, so sah ich dasselbe mit Solbrig bei den unipolaren Zellen vorwiegend an der Ursprungsstelle des Fortsatzes liegen. Bei multipolaren Zellen aus den Centren der Gasteropoden war das Pigment auch in der Regel auf die Abgangsstelle des grössten Fortsatzes beschränkt, ganz ähnlich wie das Pigment in den grossen vielstrahligen Zellen aus den Vorderhörnern der grauen Rückenmarkssubstanz der Wirbelthiere immer auf die Ursprungsstelle des sogen. Axencylinderfortsatzes beschränkt bleibt. Bei bipolaren Zellen von Helix waren in der Regel an beiden Polen Pigmentkörner abgelagert. Regelmässig nun erstrecken sich bei Gasteropoden Pigmentkörner in reikenweiser Gruppirung eine Strecke weit in den Fortsatz hinein, wie dieses auch von Solbrig näher beschrieben worden ist. - Nur in wenigen Zellen waren die Pig- 
mentkörner mehr diffus durch den Zellkörper verstreut. Das Pigment der Gasteropoden erscheint im frischen Znstande in Gestalt intensiv gelb-glänzender Körnchen; Osmiumsäure schwärzt diese Körnchen.

Da es mir bei den Gasteropoden nicht gelang, unzweifelhafte Beweise für die Existenz einer besonderen, structurlosen Zellmembran zn erhalten, habe ich die Controverse über die Membran bei Wirbellosen weiter unten bei den Würmern erörtert. Bei Hirudo med., Lumbricus agricola sowohl wie auch bei den Elatobranchien habe ich ganz unzweifelhafte Belege für das Vorhandensein einer Ganglienzellmembran beigebracht. Bei den Gasteropoden dagegen habe ich nur wiederholt an Zellfortsätzen eine bei der Präparation sich deutlich rom Fortsatz abhebende Membran gesehen (Vergl. Fig. 2 a.). An dem Zellkörper selbst sah ich nun eine oft auffallend scharfe Begrenzung des Zellleibes, die ich namentlich anf Grund meiner an frischen Präparaten und in Osmiumsäure gehärteten Gefrier-Objecten gemachten Beobachtungen nicht mit Leydig's Namen der ,erhärteten Rindensubstanz" belegen möchte, zumal der Zellfortsatz wiederholt eine unzweidentige Membran zeigte. Solbrig hat nur in einem einzigen Falle eine Membran gesehen, die sich aber nicht auf den Fortsatz weitercrstreckt. In seiner Zeichnung (Fig. 7 auf Tafel III) ist dieselbe auffallend breit gezeichnet.

Nervenstämme und Nervenfasern bei Gasteropoden.

Die Untersuchung der Nervenstämme scheitert im frischen Zustande, wie das von allen Untersuchern gleichmässig hervorgehoben wird, an der grossen Zähigkeit und Stärke des Neurilemms. Insbesondere liefern Zupfpräparate sowohl frischer als conservirter Nervenstämme aus diesem Grunde nur sehr mangelhaften Aufschluss über die feinere Zusammensetzung der Stämme aus Nervenfasern. Was zunächst den Bau der primären, starken Neurilemmscheide betrifft, so ist dieselbe, im frischen Zustande untersucht, bedeckt mit den bei Mollusken so sehr verbreitet vorkommenden Schleimzellen ${ }^{\mathfrak{1}}$ ). Diese Schleimzellen kommen auch im

1) Vergl. Flemming: Untersuchungen über Sinnesepithelien d. Mollusken, sowie Flemmings Aufsatz „Ueber die Blutzellen d. Acephalen und 
adventitiellen Gewebe der Blutgefässe bei Mollusken vor. An gewissen Nerven (Fühlernerv von Helix und Nervenstämme der Elatobranchier) hängen die Zellen weniger fest mit dem Neurilemm zusammen und man findet sie bei der Untersuchung abgestreift. Dieselben erscheinen im frischen Zustande untersucht als helle Blasen mit regelmässig excentrisch gelagertem Kern. An ganz frischen Präparaten, die in der Leibesflüssigkeit der Thiere untersucht wurden, sah ich häufig im Innern der Zellen eine Molecularbewegung. Kleine Körnchen erschienen bald an der Oberfläche des Zellkörpers, bald tauchten sie wieder unter in das Innere der Zelle. An conservirten Präparaten waren solche Körner meist in der Umgebung der Kerne sowie an der Peripherie der Zellen, an der inneren Membranwand gelegen. Das Neurilemm enthält in bindegewebiger Grundlage Muskelfasern und eine fettige aus reihenweis gruppirten Körnern bestehende Substanz. Besonders stark sind die Muskelfasern vertreten in dem sogenannten äusseren Neurilemm der Commissuren. An einem guten optischen Längsschnitt eines ganz frischen oder gut macerirten Nervenstammes sah ich nun stets eine sehr scharfe Längsstreifung; hie und da tauchten dunklere, zackige Contoure im Gesichtsfeld auf, die ohne Zweifel der Ausdruck der gleich zu besprechenden Secundärscheiden waren. An Rissstellen hat der feinstreifig erscheinende Inhalt der Nervenstämme büschelförmig in Gestalt körnig-fibrillärer Masse heraus (vgl. Fig. 10). Nur sehr selten sah ich scharf differenzirte Fibrillenbundel resp. Nervenfasern. Aus meiner nachfolgenden Darstellung des Baues der Nervenstämme wird hervorgehen, dass wir überhaupt aus Zupfpräparaten uns kein endgültiges Urtheil tuber die Beschaffenheit der Nervenfaser bei Gasteropoden bilden können. Dass aber Primitivfibrillen, eingebettet in eine körnige Zwischensubstanz den wesentlichen nervösen Inhalt bilden, die Ueberzengung habe ich schon aus einer grossen Reihe von Zupfpräparaten und guten optischen Längsschnittbildern gewinnen können. (Vgl. meine Figuren 8 und 10.) Diese Fibrillen treten gleich scharf an ganz frischen wie an macerirten Präparaten zu Tage.

Ich erwähnte bereits in der Einleitung, dass der Begriff der

Bemerkungen über deren Blutbahn. Im Archiv f. mikr. Anatomie Bd. VI 1870 und Bd. XV 1878. 
Nerven-Faser der Wirbellosen bei den meisten Untersuchern wenig scharf präcisirt ist. Selbst unbedingte Anhänger der fibrillären Structur, wie Leydig brauchen die Wörter "Faser" und „Fibrille" noch vielfach promiscue. Es muss dies um so mehr auffallen, als bereits Waldeyer in seiner oben citirten classischen Arbeit den Begriff der Nervenfaser als "Fibrillenbündel" so scharf definirt hat. Um so weniger aber dürfen wir uns wundern, wenn bei den Gegnern der fibrillären Structur grosse Verworrenheit dieser Begriffe herrschen. Nach Buchholz und Solbrig bestehen die Nervenstämme Wirbelloser aus einem Fasergemisch der verschiedensten Breitendimensionen. Buchboltz nennt eben jeden centralen Zellfortsatz ohne Weiteres "Nerven-Faser" und da Buchholz, wie bereits erwähnt, den directen Uebergang grösserer Fortsätze in periphere Nerven gesehen haben will, lag für ihn die Deutung nahe, jedes aus der Rissstelle eines Nervenstammes zu Tage tretende „F̈̈serchen" als "Nervenfaser" anzusprechen. Auch Solbrig erwähnt das Vorkommen unmessbar feiner Fasern und citirt bei dieser Gelegenheit (pag. 39) den von Waldeyer gebrauchten Namen der "Axenfibrille" Ich unterlasse nicht zu bemerken, dass Solbrig anf der anderen Seite Nervenstämme gesehen hat, die aus nahezu gleich starken Fasern zusammengesetzt erschienen, dass Solbrig ferner an der centralen Aufsplitterung zallreicher Zellfortsätze, wodurch eben die im Centrum der Ganglien gelegene körnig-fibrillïre Centralsubstanz gebildet wird, aus der wiederum die Nervenstämme das Material zu ihrem Aufbau nehmen, festhält. Nach Solbrig sind nun diese sehr verschieden breiten Nervenfasern, die er als hüllenlose Axenfasern mit scharf begrenztem Rande und homogenem Inhalt definirt, im Nervenstamm nicht unmittelbar nebeneinander gelagert, vielmehr sind sie eingebettet in eine körnige Zwischensubstanz, die Solbrig sich im lebenden Zustande als durchsichtige, zähflüssige Masse denkt.

Ich kann nun nicht umbin meine Verwunderung darüber auszusprechen, dass weder Solbrig noch einer der anderen Autoren bei der grossen Unzuverlässigkeit der Zupfbilder, welche eben durch das zähe Neurilemm bedingt ist, sich nicht die Mühe genommen haben, durch Querschnittbilder über den Bau der Nervenstämme sich Aufschluss zu holen. Wären die schönen Arbeiten von Hermann über die Nervenstämme von Hirudo früher bekannt gewesen, so hätten die Resultate Hermann's gewiss auch 
schon frther zu Nachuntersuchungen bei anderen Wirbellosen aufgefordert. Nach Hermann ist bei Hirudo das primäre Neurillemmarohr durch Secundärscheiden abgefächert: der nervöse Inhalt verläuft in nahezu gleich starken "hüllenlosen" Bündeln in diesen Fächern zur Peripherie.

Ich erwähnte bereits oben, dass ich an guten optischen Längsschnittsbildern die Contoure der Secundärscheiden erkennen konnte. Auf Grund einer Reihe von Querschnittsbildern der verschiedensten Nervenstämme von Helix pomatia glaube ich den Beweis gefuhrt zu haben, dass auch die Gasteropoden ganz ähnliche Verhältnisse darbieten wie sie Hermann bei $\mathrm{Hi}$ r udo gefunden. In Fig. 11 bilde ich den Querschnitt des Fülernerven von Helix pomatia ab, der in dieser Beziehung durchaus keine Abweichungen von anderen peripheren Nervenstämmen zeigte. Das Lumen des Nervenstammes ist durch ziemlich regelmässige Septa, die vom primären Neurilemm ausgehen, in eine Unzahl Fächer abgetheilt. Dabei ist eine gewisse Regelmässigkeit in der Anordnung der Septa unverkennbar. Dass Grössenunterschiede unter den Fächern und somit Differenzen in der Breitendimension der „Fibrillenbündel" vorkommen, ist auch wohl a priori anzunehmen. Nur möchte ich hervorheben, dass mir so starke Unterschiede unwahrscheinlich scheinen, wie sie von Buchbolz und Solbrig angegeben werden, dass insbesondere dieser Bau der Nervenstämme uns dringend auffordert den Begriff der Nervenfaser als Fibrillenbündel und den Begriff der Fibrille streng auseinanderzuhalten. Diese Secundärscheiden im primären Neurilemmarohr sind von Solbrig nicht gesehen worden; ich behalte den von Solbrig furr die Nervenfasern gewählten Ausdruck „hüllenlos" gerne bei; nur ist zu betonen, dass eben die Secundärscheiden die Function einer ,Membran" übernehmen. Verfolgt man einen peripheren Nervenstamm in seine letzten Zweige, so trifft man leicht Aeste, die aus wenigen Secundärfächern bestehen. Verlässt ein Fibrillenbündel den Nervenstamm, so übernimmt die Secundärscheide nunmehr die Rolle einer Membran. Eine Membran im Sinne der Schwann'schen Scheide kommt allerdings bei Wirbellosen nicht vor.

Dieser von mir für die Gasteropoden gefundene Bau der Nervenstämme, der also im Princip durchaus mit den von Her- 
mann bei Hirudo medic. entdeckten Thatsachen wbereinstimmt, und welcher wie ich gleich bemerken will in derselben Weise von mir bei den Muscheln angetroffen wurde, erklärt leicht die Schwierigkeiten, mit welchen die Isolirung der Nervenfasern zu kämpfen hat. In Zupfpräparaten wird an Rissstellen eben durch Druck leicht der genannte fibrilläre Inhalt aller im Querschnitt getroffenen Fächer austreten, ohne dass scharf differenzirte Fibrillenbündel zu erkennen wären. Ferner ist mit dieser Structur der Nervenstämme die Existenz der von Solbrig zwischen den Nervenfasern gesehenen $\mathrm{Zwischensubstanz}$ absolut nicht in Einklang zu bringen. Wohl aber besitzt das einzelne Fibrillenbiandel im Innern eine die Fibrillen isolirende, körnige Substanz, wie das aus allen von mir gesehenen Bildern hervorgeht.

Die als Verbindungsstränge zwischen den Schlundganglien verlaufenden sogenannten $\mathrm{Commissuren} \mathrm{zeigen} \mathrm{abgesehen} \mathrm{von}$ einem doppelten Neurilemm (einem ïusseren und inneren) und abgesehen von der characteristischen, zuerst von Leydig entdeckten Duplicität, auf dem Querschnitte durchaus die gleiche Abfächerung in Nervenfasern. Die doppelten Neurilemmascheiden sind derart angeordnet, dass in der gemeinsamen äusseren Scheide je zwei Commissurenstränge durch ein selbstständiges inneres Neurilemma. rohr geschieden sind.

Sowohl in den Nervenstämmen als in den. Commissuren kommen zahlreiche meist bipolare sogen. interponirte Ganglienzellen vor; dieselben sind insbesondere in den Anfangstheilen der Stämme nahe ihrem Ursprung aus dem Ganglion zahlreich vorhanden. In den Commissuren schienen sie mir massenhafter vertreten, als in den Nervenstämmen.

Schliesslich will ich noch bemerken, dass es mir nie gelang in Spiraltouren verlaufende Nervenfasern, wie Solbrig sie schildert, zu sehen. Solbrig hat ferner in vielen Präparaten aus den Nervencentren ganz eigenthümlich k orkzieherartig gewundene Fasern gesehen, deren nervöse Natur durch Chlorgold erwiesen wurde. (Vgl. Solbrig's Fig. 9 auf Taf. V.) Aehnliche Bildungen habe ich nur in Goldpräparaten der Magen-Darmnerven sowie der Verzweigungen des Fuhlernervs von Helix gesehen; ich stehe nicht an, diesen gewundenen Verlauf der Fasern fuir eine Wirkung der stark schrumpfenden Goldmethode zu erklären, trotzdem Solbrig diese Erklärung von der Hand weist. Bekannt- 
lich sieht man Aehnliches in vielen Goldpräparaten der verschiedensten Nerven, auch bei Wirbelthieren, und ich habe niemals bei einem anderen Reagens solche Bilder gesehen. - Aus diesem Verhalten einzelner Fasern nun aber gar auf specifische, physiologische Bedeutung zu schliessen, scheint mir denn doch wenig gerechtfertigt.

Nervenfaser und Ganglienzelle der sogenannten sympathischen Magen-Darmuerven der Gasteropoden.

Ich unterwerfe die Magen-Darmnerven der Gasteropoden einer gesonderten Betrachtung, einmal weil dieselben meines Wissens bisher von keinem Autor untersucht worden sind, und dann, weil gewisse characteristische Structurunterschiede anzuführen sind, welche in ganz analoger Weise, wie beim Sympathicus der Wirbelthiere, diese Nerven von den cerebrospinalen, wenn dieser Ausdruck für Wirbellose gestattet ist, unterscheiden. Bekanntlich hat Sigmund Mayer den Versuch gewagt, dem sympathischen System der Wirbelthiere alle und jede characteristischen, morphologisch-histologischen Unterscheidungsmerkmale abzusprechen. Die Arbeit Sigmund Mayer's ist zu neu, und scheint noch zu wenig Beachtung gefunden zu haben, als dass ihre wichtigen Consequenzen schon sollten gereift sein. Auch gebe ich gerne zu, dass für die Erkenntniss des Nervensystems Wirbelloser aus der Mayer'schen Studie der grosse Nutzen hervorgeht, in der Deutung gewisser, vielleicht durch specifische Reagentien erzeugten Bilder vorsichtig zu sein. Indessen es bleiben auch für die Magen-Darm-Nerven der Gasteropoden besondere Eigenthümlichkeiten, welche diese Nerven mit dem Sympathicus der Wirbelthiere theilen, sodass wir uns auf der anderen Seite hüten müssen, diesen anatomischen Merkmalen von vornherein jede functionelle Bedeutung abzusprechen. Leider gestattet mir die Zeit nicht, die Argumentation Sigmund Mayer's an der Hand des Sympathicus der Wirbellosen zu prüfen; ich glaube es liessen sich durch verschiedene Befunde einige der von Ma y er vorgebrachten Argumente entkräften. Indessen, ich muss mich hier darauf beschränken, die histologischen Verhältnisse darzustellen.

Zur Darstellung der Darmnerven der Gasteropoden eignen sich nur jüngere Exemplare von Helix pomatia und Arion ater, während der Darm von Helix nemorosa auch bei 
älteren Individuen zur Untersuchung geeignet ist. Ich erhielt sehr gute Goldpräparate, wenn ich den Darm kurze Zeit in concentrirte Ameisensäure, darauf etwa 10 Minuten lang in 1procentige Goldchloridlösung legte und ihn dann während 24 Stunden der Ameisensäurereduction ( $1 / 2$ verdünnte Lösung) aussetzte.

An solchen Präparaten ubberraschte die erstaunliche Fülle grosser und kleiner Ganglienzellen. Die Nervenstämme waren förmlich bedeckt mit zum Theil riesigen Zellen. Feinere Structurbilder waren nattirlich mit der Goldmethode nicht za erzielen; nur an blasser tingirten Präparaten erschienen die Nervenstämme und - Fasern oft sehr deutlich fibrillär. Die Zellen waren meist dunkeler tingirt. Ich wählte nun andere Methoden, die mir auch besseren Aufschluss über feinere Structurverbältnisse gaben. Ich legte ein Stück Darm 3 Minuten in concentrirte Essigsäure und tingirte die Präparate dann 24 Stunden lang mit starkverdünnter carminsaurer Ammoniaklösung; hierauf wurde das Darmepithel heruntergepinselt und die Nerven traten mit uberraschender Klarheit zu Tage. Die Fig. 8 Taf. $\mathrm{V}$ ist nach einem solchen Präparat gezeichnet. Die Nerven-Stämme; -Fasern und Zellen waren gleichmässig fibrillär; zwischen den Fibrillen war eine feinkörnige Substanz leicht zu erkennen. Diese Klarheit der Bilder wurde wesentlich gefördert durch den Mangel kernhaltiger Neurilemmascheiden, welche der Untersuchung der cerebrospinalen Nerven der Gasteropoden so sehr hinderlich sind. Es waren innerhalb des primären kernhaltigen Neurilemmarohrs keine Secundärscheiden zu erkennen. Bei der grossen Deutlichkeit der Bilder hätte man diese auch am optischen Längsschnittsbilde nicht übersehen können.

Die Ganglienzellen besassen eine als scharfe Contour leicht zu erkennende Membran; ich betone dies, da ich an centralen Zellen die Membran nicht habe mit Bestimmtheit nachweisen können. Auch Hermann bat an sympathischen Nerven von Hirudo medic. eine Membran gesehen. Die so zahlreichen Ganglienzellen standen ohne Frage in freilich nicht aufgeklärtem Zusammenhange mit dem Auftreten neuer Nervenfasern resp. mit dem Abgehen von Fibrillenbündeln von den Nervenstämmen. Hie und da beobachtete ich grosse Zellen, welche einen Fortsatz zum Nervenstamm schickten, während der andere Fortsatz zwischen Muskelfasern verschwand. 
Um kurz zu recapituliren, so sind die sympathischen Nerven der Gasteropoden also ausgezeichnet durch die zahlreiche Menge in allen ihren wesentlichen Attributen mit centralen Zellen ibbereinstimmenden Ganglienzellen, durch die Anordinung in der Verbindung von Nerv und Zelle, ferner durch das Fehlen der Secundärscheiden in den Nervenstämmen. Der sympathische Nervenstamm wäre demnach als riesiges Fibrillenbundel aufzufassen.

Ueber den feineren Bau der Centralganglien sowie über den centralen Ursprung der Nervenfasern bei Gasteropoden.

Leider muss ich darauf verzichten, schon jetzt den Versuch einer topographisch-histologischen Schilderung der Centralganglien zu machen. Die Würdigung der zahlreichen widersprechenden Angaben über die Structurverhältnisse der nervösen Elementarbestandtheile machten mir dies unmöglich.

Ehe ich den gröberen Bau der Ganglien schildere, sei mir gestattet, kurz auf die Frage nach der Existenz sogenannter Commissuren zwischen centralen Ganglienzellen einzugehen. Dass unter den sogenannten sympathischen Ganglienzellen der Magen-Darmnerven zahlreiche Verbindungen durch Zellfortsätze resp• Nervenfasern stattfinden, darf uns nicht auffallen, wenn wir uns der analogen Verhältnisse beim N. Sympathicus der Wirbelthiere erinnern. Auch in anderen terminalen Endplexus bei Wirbellosen kann gar kein Zweifel darüber herrschen, dass solche intercellulare Verbindungen vorkommen. Viel unsicherer aber und von jeher in Zweifel gezogen sind die Angaben tiber Commissurfäden zwischen centralen Ganglienzellen. Nähere Angaben über das Vorkommen derselben finde ich nur bei Walter ${ }^{1}$ ) und Waldeyer ${ }^{2}$ ). W alter beschreibt sowohl sogenannte Commissuren zwischen zwei grösseren Zellen, als er auch durch fortgesetzte Verbindung grösserer und kleinerer Zellen eine neue Ansicht über den Ursprung: und centralen Verlauf der Nervenfasern aufgestellt hat. Waldeyer hat ebenfalls in seinem fast gleichzeitig erschienenen

1) Walter: Vgl, oben 1. c.

2) Waldeyer: Vgl. oben 1. c. 
Werke solche Verbindungen centraler Zellen beschrieben und abgebildet. Leydig berihhrt in seinem bertihmten Werke diese Verhältnisse nicht, und Buchholz sowie Solbrig haben das Vorkommen derartiger Gebilde auf das lebhafteste bestritten.

In den vielen Zupfpräparaten, die ich aus den centralen Ganglien von Helix pomatia, Helix nemorosa und Arion ater angefertigt habe, ist mir auch nie eine derartige Verbindung zu Gesichte gekommen. Dagegen besitze ich gut aufgehellte Schnitte in Alcohol gehärteter Ganglien, wo in ganz unzweifelhaften Fällen grössere, multipolare Zellen von Helix pomatia sowohl untereinander als auch mit kleineren Ganglienzellen durch Zellfortsätze in Verbind ung treten. Auch will ich gleich im Voraus bemerken, dass ich bei den Elatobranchien, Anodonta, Mytilus und Unio in zahlreichen Zupfpräparaten derartige Verbindungen beobachtet habe, worauf ich weiter unten noch zurückkomme.

Ehe ich nunmehr die Frage nach dem Ursprunge der Nervenfaser erörtere, will ich kurz den gröberen Bau der Ganglien schildern und zwar habe ich das Ganglion infraoesophageum von Helix pomatia im Auge. Vergleicht man nur eine kleine Reihe in verschiedenen Ebenen durch das Ganglion gelegter Schnitte, so lässt sich im Allgemeinen sagen, dass dasselbe aus einer dicht mit Ganglienzellen der verschiedensten Grösse erfüllten Rindenzone, sowie aus dem im Centrum gelegenen Ballen körnig-fibrillärer, nervöser Centralsubstanz besteht. Die Ganglienzellen berühren einander nicht unmittelbar. Dunne, gut ausgeschuittelte Schnitte zeigen nämlich, dass die neurilemmatische Wand zahlreiche mit Bindegewebskernen bedeckte Septa in die Rindenzone hineinschickt. Dadurch gewinnt letztere einen vollständig folliculären Habitus; dieser zuerst von Leydig für das Gehirn der Hirudineen gewählte Ausdruck passt auch insofern, als gewisse Gruppen von Ganglienzellen, die in gemeinsamer Bindegewebskapsel liegen, durch innigere Aneinanderlagerung eine ausgesprochene Zusammengehörigkeit verrathen. Die Ganglienzellen liegen nun in den Maschenräumen dieses Fachwerks immer so gruppirt, dass die grösseren mehr peripher, die kleinsten dagegen an der Peripherie der Centralsubstanz gelagert sind.

Dass nun die grosse Mehrzahl der Zellfortsätze durch fortgesetzte Theilung sich auföst in die körnig-fibrilläre Centralsub- 
stanz, darüber liefern sehon gute Zupfpräparate oder besser noch Situs-Schnittpräparate ganz unzweifelhaften Aufschluss. Ferner erkennt man an guten Schnitten, dass aus der körnig-fibrillären Centralsubstanz die abgehenden Nervenstämme ihre Inhaltmasse beziehen.

Ueber dieses zuerst von Leydig bei den Egeln, Insecten und Schnecken aufgefundene Schema für den gröberen Bau der Nervencentra Wirbelloser herrscht denn auch bei allen Untersuchern völlige Uebereinstimmung. Nur gab das physiologische Bedürfniss, anch im Centralorgan durch das labyrinthische Fasergewirr der Centralsubstanz hindurch eine leitende Verbindung der Nervenfasern mit den Ganglienzellen anatomisch herzustellen, Anlass zur Aufstellung mehrerer Hypothesen. Unter den neueren Untersuchern hat vor Allem Solbrig diese Verbältnisse am eingehendsten erörtert.

Solbrig und andere Autoren bezeichnen die oben geschilderte Verbindung der Ganglienzellen mit den aus dem Centrum entspringenden Nervenfasern als den ,indirecten Uebergang der Zellfortsätze in periphere Nerven“. Ich will den Ausdruck ,indirect", der mit Rücksicht auf die Zwischenlagerung des anastomotischen centralen Fasernetzes gewählt ist, beibehalten, trotzdem ich denselben für misslich halte, weil, wie wir alsbald sehen werden, der Uebergang eines Zellfortsatzes in die Centralsubstanz wiederum verschieden vor sich gehen kann.

Als directen Uebergang eines Zellfortsatzes in eine $\mathrm{zar}$ Peripherie verlaufende Nervenfaser hat man jenen Fall bezeichnet, wo der breite Fortsatz einer grossen, unipolaren Zelle ungetheilt die Centralsubstanz durchsetzen soll, um als Nervenfaser weiter zu verlaufen. Solche Fälle sind zunächst von Leydig in den Bauchmarksganglien von Hirudo beobachtet. Aebnliche Angaben werden von Helmholtz, Will, Buchholz, Walter und Solbrig berichtet. Waldeyer bestreitet dagegen entschieden die Richtigkeit dieser Beobachtungen. Für die Gasteropoden nun ist kein einziger solcher Fall mit unzweifelhafter Sicherheit direct nachgewiesen. Vielmehr ist diese Ansicht anf allerdings sehr einleuchtenden Reflexionen basirt. Man begegnet nämlich (ich schliesse mich hierin an die Angaben von $\mathrm{Buchholz}$ und Solbrig an) in Zupfpräparaten sehr häufig Fortsätzen, deren auffallende Länge bei gleichbleibendem Caliber in scheinbarem Contrast zu 
der Breite der im Centrum gruppirten Ballen körnig-fibrillärer Substanz steht. Man gewinnt ganz die Ueberzeugung, dass der Fortsatz ungetheilt die Centralsubstanz durchsetzt, um als Nerven. faser in irgend einen Nervenstamm einzutreten. Mir ist es ebensowenig wie Buchholz und Solbrig geglückt, einen solch directen Uebergang wirklich zu sehen. Und meiner Ansicht nach muss diese Frage so lange als unerledigt angesehen werden, als bis die Thatsache durch Schnittpräparate unwiderleglich dargethan ist, und das wird nur durch eingehende topographische Studien möglich sein.

Solbrig rechnet auch zu dem ,directen Uebergang“ die von ihm beobachteten seltenen Fälle, wo sogenannte Kernkörperfortsätze ungetheilt weiterliefen, ohne feinere Fäserchen abzugeben. Solbrig hat nur ein einziges Mal einen solchen Fortsatz auf eine grössere Entfernung verfolgen können und hat ferner durchaus keine stringenten Beweise für seine „Vermuthung" beigebracht. Mir ist, wie schon oben erwähnt, nie ein Kernkörperfaden weder bei Gasteropoden, noch bei Würmern und Muscheln zu Gesichte gekommen.

Ich deutete bereits an, dass auch über den Modus des Verlaufs eines Zellfortsatzes bis zur Verschmelzung mit der anastomotischen Centralsubstanz verschiedene Ansichten aufgestellt wurden. Der oben geschilderte sogenannte ,indirecte Uebergang" vollzieht sich nach allen Untersuchern in der grossen Mehrzahl der Fälle in der Weise, dass sich der Fortsatz durch fortgesetzte Theilung auflöst in das fibrilläre Reticulum der Centralsubstanz. Schon der Umstand, dass sämmtliche Zellfortsätze nach dem Centrum hin convergiren, weist auf diesen Modus hin. Nach Walter und Waldeyer können nun aber auch kleinere Ganglienzellen in den Verlauf eines Fortsatzes eingeschaltet sein. Bei Gasteropoden habe ich allerdings Anastomosen zwischen grösseren und kleineren Ganglienzellen beobachtet, indessen gelang es mir nie, den schliesslichen Zusammenhang mit der fibrillären Centralsubstanz nachzuweisen. Indessen bemerke ich schon hier, dass mir dieses bei den Muscheln wiederholt selbst in Zupfpräparaten geglückt ist.

Die für die centralen Ganglien der Gasteropoden in gleicher Weise, wie für die Centren der Muscheln geltende Regel, dass im Allgemeinen eine der Grösse nach stufenweise Gruppirung der Ganglienzellen vorherrscht, so zwar, dass die klei- 
neren und kleinsten stets unmittelbar an der Peripherie der centralen Fasersubstanz gelagert sind, weist vielleicht auch für die Gaste ropoden auf die Möglichkeit einer solchen leitenden Verbindung unter den Ganglienzellen hin, wie sie von Walter und Waldeyer ganz allgemein angenommen wurde. Ich bemerke indessen, dass die Centren der Gasteropoden in Wirklichkeit in der Gruppirung der Ganglienzellen durchaus nicht so einfache Verhältnisse darbieten, wie die Muscheln, für welch' letztere ich auf Grund meiner zahlreichen Beobachtungen den zuletzt erwähnten Uebergangsmodus der Zellfortsätze (mit Einschaltung kleinerer Ganglienzellen) durchaus als die Norm aufstellen muss.

Der Fühlernerv von Helix pomatia mit dem Fuhlerganglion und den terminalen Endausbreitungen.

Die Anatomie des Fühlernerven von Helix pomatia hat in dem bereits citirten Aufsatze Flemming $\mathrm{s}^{1}$ ) eine bis ins feinste Detail gehende Darstellung gefunden, sodass es einer besonderen Rechtfertigung bedarf, wenn ich diesen Nerven auf die hier erörterten Structurverhältnisse hin einer erneuten Betrachtung unterziehe. Einmal hoffte ich gewisse, von Flemming noch offen gelassene Fragen über ganz eigenthümliche Nervenelemente dieser Gegend durch neue Untersuchungen beantworten zu können, und dann lag mir daran, in dem Verhalten der terminalen Ausbreitungen dieses Sinnesnerven eine weitere Stuitze für die Lehre vom fibrillären Bau zu gewinnen, wie dies in analoger Weise bei Wirbelthieren von M. Schultze geschehen ist. Bei Wirbellosen ist das Verhalten der Nerven an der Peripherie bisher von keinem Forscher gelegentlich der Erörterung der M. Schultze'schen Theorie untersucht worden, und Flemming ${ }^{2}$ ) ist überhaupt der Erste gewesen, welcher Nervenendigungen bei Wirbellosen eingehender beschrieben hat.

1) Flemming: Untersuchungen über Sinnesepithelien der Mollusken. Archiv f. mikrosk. Anat. Bd. VI, 1870. Derselbe: Die haaretragenden Sinneszellen in der Oberhaut der Mollusken. Daselbst Bd. V. 4. Derselbe: Zur Anatomie der Landschneckenfühler etc. Zeitschr. f. wiss. Zoologie 1872.

2) a. a. 0. p. 143. 
Rticksichtlich der Untersuchungsmethoden verweise ich auf die von Flemming a. a. 0 . gegebenen Rathschläge and Winke, an die ich mich streng gehalten habe. Auch bin ich durch die Glite Flemmings in den Stand gesetzt, an der Hand seiner eigenen vorzüglichen topographischen Präparate meine Untersachung controlliren zu dürfen.

Flemming ${ }^{1}$ ) schildert den Stamm des Fühlernerven als aus feinen, blassen Fasern bestehend, welche uberall eingebettet sind in dicht feinkörnige Masse, weleh' letztere nach Fle mming: rundliche Kerne einschliesst, eine bestimmte Anordnung in Zellen aber nicht erkennen lässt. Denselben Bau zeigt der hintere und centrale Theil des Fublerganglions, der denn auch von Flemming als einfache Verdickung des Nerven in Anspruch genommen wird. Ich konnte mich an Flemmings eigenen und an selbstgefertigten Längs- und Querschnitten überzeugen, dass in Bezug auf den Bau des Nerven noch mehr zu sehen ist, als Flem ming beachtet und beschrieben hat.

Zunächst zeigt der Stamm des Fühlernerven bis zum Eintritt ins Ganglion einen durch Secundärscheiden abgefächerten Bau im primären Neurilemmarohr, wie ich solches für die verschiedensten Nervenstämme der Gasteropoden nachgewiesen habe. Sehr häufig sieht man an den stärkeren Scheidefächern deutliche Kerne, nnzweifelhaft bindegewebiger Natur. Aber auch in den Maschen des neurilemmatischen Fachwerks sieht man hie und da zwischen den nervösen Fibrillen kleine meist spindelförmige Zellen, die ich nach Analogie meiner Befunde an anderen Nervenstämmen für sogenannte interponirte, kleine Ganglienzellen halte.

Auf die Regelmässigkeit in der Abfächerung des Nervenstammes wies ich bereits oben hin. Die in den Scheidefächern verlaufenden "nackten" Nervenbiundel zeigen sowohl bei der Untersuchung im frischen Zustande, wie nach Anwendung der gebräuchlichen Reagentien deutlich fibrillären Bau. An optischen Längsschnitten erkennt man neben dieser feinen Längsstreifung die gröberen Contoure der Secundärscheiden.

1) Nach Flemming hat Simroth in seiner Arbeit: „Ueber die Sinneswerkzenge unserer einheimischen Weichthiere" (in d. Zeitschr. f. wiss. Zoologie Bd. XXVI 1876) Nervenendigungen bei Wirbellosen untersucht, ohne indessen näher auf feinere nervöse Structurverhältnisse einzugehen. 
An der Eintrittsstelle in das Fuhlerganglion nun erreichen die Secundärscheiden ihr Ende. Die Fibrillenbtundel strahlen in ein Strickwerk feinster Fibrillen aus. Im hinteren und centralen Theile des Ganglions kommen in dieser „nervösen Centralsubstanz" nur spärliche spindelförmige oder vielstrahlige, kleine Ganglienzellen vor. Dagegen liegen an der Peripherie die Nervenzellen in mehreren continuirlichen Schichten angehäuft. Die mehr centralwärts gelegenen, grösseren Zellen senden ihre oft zahlreich verästelten Ausläufer in das im Centrum gelegene, fibrilläre Fasergemisch. Flemming bezeichnet daher die centrale Sub$\operatorname{stanz}$ schlechthin als Nervenmasse, gegenüber dem peripherisehen Ganglienstratam. Dieser Bau des Fühlerganglion stimmt, abgesehen von der auffallenden Kleinheit der Ganglienzellen, so sehr mit der Structur der übrigen nervösen Centren der Gasteropoden überein, dass man das Ganglion gewiss mit vollem Recht als ein vorgeschobenes Centrum für die Function des Fühlernervs betrachten darf.

Von der vorderen Peripherie des Ganglions nun strahlt der nervöse Inhalt in mehreren Strïngen, die alsbald durch Theilung sich vermehren, in das Gewebe des Füblerknopfs aus. Diese Stränge sind dermaassen dicht mit kleinsten Ganglienzellen besetzt, dass der von Flemming gewählte Ausdruck der "Nervenzellenzüge" sehr passend erscheint. Auf dem Querschnitt wiederholen diese Stränge durchaus im Kleinen den oben beschriebenen Bau des Ganglions, insofern die Nervenzellen schichtweise an der Peripherie der centralen, körnig-fibrillären Nervenmasse gelagert sind. Bei der weiteren peripherischen Verästelung nun schwellen die stärkeren Nervenzellenzüge wierderum zu gangliös en Lagern an, aus deren Mitte dann die letzten isolirten Stränge pallisadenartig dichtgedrängt bis zur subepithelialen Muskelschicht heranziehen. In meiner Figur 25 stellt g. L. ein solches gangliöses Lager mit centraler, körnig-fibrillärer Nervenmasse dar; an der Peripherie liegen in mehreren Schichten kleine und grössere Ganglienzellen, deren Ausläufer theils nach dem Centrum hin convergiren, theils in die abgehenden Nervenzellenzigge zweiter Ordnung zu verfolgen sind. Ueber die letzte Endigungsweise der an der Basis der Epithelien sich gabelig verästelnden Nerven kann ich mir kein Urtheil erlauben, da alle von mir gemachten Goldpräparate misslangen. Erwähnen will ich nur noch, dass 
der in Osmiumpräparaten anffallend scharf zur Längsaxe der Epithelien längsgestrichelte, breite Cuticularsaum durch Gold vollständig geschwärzt wurde, wie sich auch in diesen Präparaten immer an der Basis der Epithelzellen eine von Gold tingirte, körnige Zone vorfand (vgl. Fig. 26). Die Verästelung der Nervenzellenzüge lässt sich am Klarsten an feinen Osmiumschnitten verfolgen (vgl. Fig. 25). Aus dem gangliösen Lager streben drei Nervenziuge zur subepithelialen Muskelschicht. Hier verästeln sich dieselben gabelig und man sieht einzelne Fibrillenbündel zwischen je zwei Epithelzellen aufsteigen. Die letzte Endigung der Fibrillen ist von Flemming ${ }^{1}$ ) an den von ihm entdeckten "Nervenendkölbchen", welche zwischen den Epithelzellen gelagert sind, nachgewiesen worden. Ich habe leider keine Zeit gefunden, die Nervenendigungen zu untersuchen; auch war es nur meine Absicht, an peripheren Nerven Wirbelloser die terminaJe Aufsplitterung in Fibrillen zu sehen, da, wie bereits erwähnt, von keinem der neneren Bearbeiter der Neurologie Wirbelloser dieses Verhalten Beriicksichtigung gefunden hat bei der Discussion der M. Schultze'schen Theorie. Za dem Zweck untersuchte ich auch andere, höchst eigenthümliche Gewebselemente im Fühlerknopf von Helix, deren nervöser Character zuerst von Flemming wahrscheinlich gemacht wurde. Flemming sagt (pag. 444 a. a. 0 .) über diese Bildungen : „Es sind einzelne Züge grosser opaker, sehr feinkörniger, dicht aneinanderlagernder Zellen von länglich-runder oder Flaschenform, deren zugespitzte Enden sich zu langen Ausläufern ausziehen. Sie liegen der Peripherie des Ganglions and der von diesem sich forterstreckenden Lager dicht an und es scheint, als ob ihre Ausläufer unmerklich in die Ganglienstrata tibergehen." Flemming weist den Gedanken, diese Zellenstränge für Drüsenzellen zu halten, zurück (pag. 445) und sagt: "sie scheinen mir am Ersten nervöse Elemente, dann also eine weitere Form von Ganglienzellen zu sein. " In einer spätern Arbeit ${ }^{2}$ ) hat F lemming dann durch die Hénocque'sche Goldbehandlung die nervöse Natur dieser Gebilde nahe gelegt.

1) Flemming: Die haaretragenden Sinneszellen in der Oberhaut der Mollusken. Archiv f. mikr. Anat. Bd. V. pag. 433.

2) Flemming: Zur Anatomie der Landschneckenfühler etc. (Zeitschr. f. wiss. Zoologie 1872). 
Diese eigenthümlichen Zellen nun kommen sowohl an der vorderen Peripherie des Fühlerganglions zwischen den Nervenzellenzügen in grossen Lagern eng aneinandergedrängt vor, als sie auch in kleineren Gruppen die ganze parietale Wand des sogenanten Fuhlerraums (vgl. Flemmings Fig. 1 auf Taf. XXV im VI. Bande dieses Archivs) bedecken; in geringerer Anzahl sind sie auch an der visceralen Wand des Fühlerraums vertreten. In Goldpräparaten überzeugt man sich leicht, dass die Zellen aller drei Bezirke einander durchaus gleichen and sämmtlich als nervöse Elemente zu betrachten sind.

Die an der Aussenseite des Fühlerraums gelegenen sind nun aber durch den Musculus Retractor vom Stamm des Fihlernerven getrennt und ist schon deshalb eine leitende Verbindung zwischen ihnen und dem Fiihlernerven absolut undenkbar. Auch konnte ich nirgends zwischen den an der vorderen Peripherie des Ganglions gelegenen Zellenlagern und dem Fühlernerven eine Spur des Zusammenhangs nachweisen; wohl aber waren die einzelnen Zellengruppen häufig untereinander durch Nervenfaserbïndel verbunden. Wir müssen also annehmen, dass auf irgend welchen noch unbekannten Bahnen eine leitende Verbindung rückwärts nach dem Centrum vorhanden ist. Aber auch diese vorausgesetzt, trägt schon die ganze Anordnung dieser durch Nervenfasern untereinander verbundenen Zellengruppen eine sehr auffallende Eigenthümlichkeit zur Schau. Man möchte sie ibrem Habitus nach am ehesten noch sympathischen Nervengeflechten vergleichen, wenn nicht der unzweifelhafte Zusammenhang ihrer Ausläufer mit dem Hatepithel ihnen eine sensibele Funktion zuschriebe. Ehe ich indessen auf dies letztere Verhalten eingehe, will ich andere von mir an diesen Zellengruppen gefundene, höchst auffallende Structurverhältnisse schildern.

In schwach tingirten Goldpräparaten zeigen diese Zellen eine äusserst zierliche Granulirung. Der Zellkörper ist förmlich überladen mit kleinen, stark Licht brechenden Körnchen. An den langgestreckten Zellfortsätzen sieht man eine sehr regelmässige Anordnung dieser Körner, insofern dieselben auf weite Strecken hin perlschnurartig aneinandergereiht theils zwischen, theils auf den nervösen Fibrillen gelagert waren (Vergl. Fig. 27). Nicht selten waren die Fibrillen streckenweise „nackt" resp. körnchenfrei, dann trat plötzlich die körnige Substanz 
an ihnen wieder auf. Anfangs glaubte ich eine specifische GoldWirkung vor mir zu haben, indessen wurde dieser Argwohn beseitigt durch die grosse Uebereinstimm ung der Bilder, welche ich mit anderen Reagentien erhielt.

In Chromammonpräparaten waren die Körner gleich regelmässig angeordnet; durch 0 smiumsäure wurden dieselben zwar etwas dunkeler gefärbt, behielten die starke Lichtbrechung aber bei. Als ich nun gar diese Körner auch in ganz frischen Zupfpräparaten, die in der Leibesflüssigkeit der Thiere untersucht wurden, vorfand, zweifelte ich keinen Augenblick, dass hier eine ganz specifische, bisher von mir in keinem anderen Nervenpräparate Wirbelloser gesehene Substanz vorlag. Und zwar wurde ich sofort an die bereits oben angedeutete Entdeckung Flemmings ${ }^{1}$ ) erinnert. Flemming beschreibt an den letzten Verzweigungen der Mantelnerven von Mytilus in Osmiumpräparaten eine, granulirte Substanz", welche hier in derselben zierlichen Anordnung zwischen den Fibrillen gelagert war und welche, nach Mittheilung ron Seiten Flemmings, auch an frischen Gefrierschnitten in derselben Weise zu sehen ist.

Nachdem ich durch die Giute Flemming's in den Stand gesetzt war, seine Präparate mit den von mir gesehenen Bildern zu vergleichen, wurde ich in der Annahme bestärkt, dass es sich in beiden Fällen um eine ganz ähnliche Substanz handelte. Flemming äussert sich in der genannten Arbeit nicht näher tiber die etwaige Natur und Bedeutung dieser interfibrillären Körner. Indessen kann ich nach mïndlicher Mittheilung berichten, das Flemming in denselhen eine myelinähnliche Substanz vermuthet. Trotzdem die Körner durch Osmiumsäure nicht geschwärzt werden, möchte ich dieser Ansicht beitreten. In ähnlicher, wenn auch minder ausgeprägter Anordnung sah ich auch in den letzten Ausläufern der Nervenzellenz üge des Fühlernerven diese Substanz auftreten. (Vrgl. g. s. in Figur 25.)

Auch will ich im Voraus bemerken, dass ich in den Nervenstämmen von Anodonta, Unio und Mytilus nach Anwendung von Osmiumsäure eine intensiv schwarz gefärbte Substanz in regelmässiger Weise sowohl interfibrillär als "intracellular" beobachtet habe; wenn nun auch diese letztere eben wegen der

1) Vgl. unten den Abschnitt über die Elatobranchier. 
bekannten Osmiumreaction und ihrer specifischen Tropfenform mehr Anrecht hat als "myenlinartig" bezeichnet $\mathrm{zu}$ werden, so möchte ich doch an der oben von Flemming ausgesprochenen Vermuthung festhalten; zumal alle Charactere dieser Substanz für eine scharfe Sonderung von der gewöhnlich nach M. Schultze sogenannten ,interfibrillären" Substanz sprechen. Berechtigen nun schon diese specifischen Structurverhältnisse der genannten Zellen ihnen eine von der des Fühlernerven zu trennende Function beizumessen, so werden wir in dieser Annahmè noch weiter bestärkt durch das Verhalten der Fortsätze dieser nervösen Gebilde. - Im eigentlichen Fiihlerknopf kommen diese Zellen unter der glatten Epitheldecke nicht vor. Dagegen liegen sie gruppenweise an der Innenwand des Hautmuskels und senden hier ihre Fortsätze durch das Muskelstratum hindurch; innerhalb des letzteren splittern sich die Fortsätze auf, verlieren die characteristische körnige Substanz and die "nackten" Fibrillen streben zur Basis des Epithels der rundlich-warzigen Hautpapillen. (In der Figur ist das Epithel nicht mitgezeichnet.) Isolirte Fibrillen verschwinden zwischen den Epithelzellen; dem Modus ihrer Endigung habe ich auch hier nicht weiter nachgeforscht. Schon die Differenz der Epithelien bereehtigt, den verschiedenen Nervenelementen specifische Functionen zuzuschreiben; welcher Art aber die Function der hier geschilderten eigenthümlichen Ganglienzellgruppen sei, darüber wage ich keine Vermuthung auszusprechen, zumal die physiologische Function des "Schnecken-Fühlers" noch durchaus controvers ist.

Erwähnen will ich noch, dass ich wiederholt im subepithelialen Stratum kleine spindelförmige Nervenzellen mit derselben characteristischen Granulirung beobachtet habe; während der eine Fortsatz im Epithel sich vorlor, versehwand der andere nach verschieden langem Verlauf im Muskelstratum. Auch „unipolare“

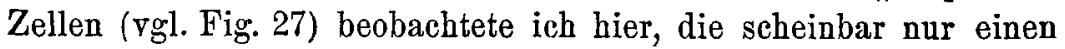
Fortsatz zur Peripherie, d. h. zum Epithel entsendeten.

\section{Das Nervensystem der Elatobranchien.}

Ueber die Histologie des Nervensystems der Elatobranchien finden sich in der Literatur nur ganz vereinzelte Notizen, welche von einigen Forschern gelegentlich ihrer Studien an anderen Ge- 
weben dieser Thierklasse angefuhrt werden. So beschreibt Walther Flemming ${ }^{1}$ ) an den peripherischen Verästelungen des Mantelnerven von Mytilus edulis einen Zusammenhang feiner Nervenreiser mit den haretragenden Sinneszellen der Mantelzacken. In dem reich mit kleinen Ganglienzellen besetzten Endplexus waren Nervenfasern und Zellen dicht bedeckt mit reihenweis aneinandergeketteten Körnchen; Osmiumsäure färbte die Körnchen. Flemming constatirte auch an frisch untersuchten Präparaten diese schon oben erwähnte „zierliche Granulirung", ohne indess a. a. O. seine Ansicht uber die Natur dieser Substanz weiter auszusprechen.

Was zunächst die Anatomie des Nervensystems der Muscheln betrifft, so habe ich die Nomenclatur der im Bronn'schen Werke ${ }^{2}$ ) gegebenen Darstellung Duvernoy's entlehnt. Nach Duvernoy besitzen sowohl Anodonta wie Unio und Mytilus ein vorderes, ein mittleres oder Pedal- und ein hinteres Ganglienpaar, die sämmtlich durch Commissuren resp. Verbindungsstränge untereinander verbunden sind.

Die Magen- und Darmnerven entspringen bei Anodonta und Unio vom Verbindungsstrang zwischen vorderem und mittlerem Ganglion, bei Mytilus dagegen aus dem Strang zwischen vorderem und hinterem Ganglion. Mytilus besitzt ferner noch 2 kleine accessorische, vordere Ganglien.

Ich habe bei den drei oben genannten Repräsentanten dieser Thierclasse die drei grossen Ganglien sowie die Verbindungsstränge und peripheren Nerven untersucht. Von Mytilus edulis untersuchte ich ferner auf die hier erörterten Structurverhältnisse hin den Mantelnerv mit seinen peripheren Terminalverästelungen.

Zupfpräparate untersuchte ich sowohl im frischen $\mathrm{Zu}$ stande, als nach Anwendung der Osmiumsäure, des Ammonium bichromicum etc. Vom Mantelnerv stellte Flemming mir eine Serie seiner ausgezeichneten Präparate zur Verfïgung.

1) Walther Flemming: Untersuchungen über Sinnesepithelien der Mollusken. Bd. VI des Archivs f. mikr. Anat. 1870. Derselb e: Ueber Bindesubstanz und Gefässwandung im Schwellgewebe. Archiv f. mikr. Anatomie Bd. XIV. $187 \pi$.

2) Bronn: Classen und Ordnungen der Weichthiere. III. Bd. Leipzig und Heidelberg 1862. 
Beim Herauspräpariren des leicht zu uberschauenden Nervensystems ron Anodonta, Unio pictorum oder Mytilus edulis iberrascht die intensive, braungelbe Färbung der Ganglienknoten, welche bedingt wird durch die bei Muscheln ganz character ist is che und nur geringen, individuellen Schwankungen unterworfene Pigmentirung der Ganglienzellen. Bringt man nun ein Ganglion frisch in der Leibesflissigkeit der Thiere auf den Objectträger, so ïberzeugt man sich leicht bei schwacher Vergrösserung, dass das Pigment vorzugsweise in der Randzone des Ganglion abgelagert ist. Bei stärkerer Vergrösserung erkennt man nämlich, dass die Ganglienzellen, welche sich als die Träger des starken Pigmentes erweisen, in mehreren Schichten dichtgedrängt an der Peripherie gelagert sind und zwar nimmt die Grösse der Zellen nach dem Centrum hin stufenweise ab. In der Mitte des Ganglions sieht man nur körnig-fibrilläre Masse.

Es kehrt somit auch hier bei den Muscheln der schon wiederholt beschriebene, einfache Bau der nervösen Centren wieder; nur gestaltet sich die Structur der kaum hirsekorngrossen Ganglien bei den Elatobranchiern weit einfacher noch als bei Gasteropoden und Würmern, insofern jede Abfächerung der Inhaltsmasse durch bindegewebige Septa hier vermisst wird.

Zerzupft man nun ein solches Ganglion, so ist das ganze Gesichtsfeld alsbald erftillt mit kleinen und kleinsten Ganglienzellen, zu deren guter Isolirung stark verdünnte Chromammoniumlösung oder 0,05 procentige Osmiumsäure vortreffliche Dienste leistet.

Betrachten wir zunächst eine jener grösseren, der Mebrzahl nach unipolaren Zellen aus der Randzone des Ganglions, so staunen wir alsbald über die förmliche Ueberladung der Zellen mit stark lichtbrechenden goldig-glänzenden Pigmentkörnern. Die Ablagerung des Pigmentes war bei älteren Individuen massenhafter, massenhafter wiederum bei Unio und Anodonta, als bei Mytilus. Häufig war neben dem Pigment nur nuch der meist fein gekörnte Kern nebst einer ganz schmalen Randschicht der eigentlichen Zellsubstanz dem Auge frei zugängig. Wo die letztere in grösserer Ausdehnung gesehen werden konnte, zeigte dieselbe sowohl im frischen wie conservirten Zustande concentrische resp. fibrilläre Streifung (vgl. die Fig. 12, 14 u. 15). 
Die glänzenden Pigmentkörner setzten sich reibenweise eine Strecke weit in den Fortsatz hinein fort. Bei Anodonta und Unio sah ich sehr häufig neben diesen glänzenden Pigmentkörnern grössere, doppeltcontourirte, myelinähnliche Tröpfchen. Nicht selten war die Zelle mit mehreren grösseren Tropfen vollständig erfüllt. Solche Zellen erinnerten flichtig an "atrophische Fettzellen" (vgl. Fig. 13). Mit Osmiumsäure bräunten sich die Tröpfehen und zeigten dann häufig eine centrale Abflachung ana$\log$ den menschlichen rothen Blutkörperchen.

Neben diesen unipolaren Zellen nun trifft man bei den Muscheln nicht viel seltener auch auf grössere multipolare Ganglienzellen. Entsprechend der auffallenden Kleinheit der Nervenzellen der Muscheln im Allgemeinen war das Caliber der kleineren Zellfortsätze häufig so fein, das man sie für isolirte Fibrillen bätte halten mögen, wenn nicht die grosse Vulnerabilität dieser tiberaus zarten Elemente iuberhaupt zu grosser Vorsicht in der Deutung etwaiger Schrumpfwirkungen aufgefordert hätte. Die Nervenzellen der Elatobranchien bleiben an Grösse weit hinter denen der Würmer und vor Allem der Gasteropoden zurück. Bei Anod onta mass ich Zellen mit 0,06 Längen- und 0,04 mm Breitendurchmesser. (Unio 0,04 L. 0,018 B.; Mytilus nur 0,02 L. 0,009 mm B.)

Auch bei den Muscheln gelang es mir sichere Beweise für die Existenz einer besonderen structurlosen Zellmembran zu sammeln; ich fand nämlich wiederholt in Präparaten leere, blasenähnliche Gebilde mit spärlich daran haftender körnigfibrillärer Substanz, die ich nur als leer gewordene Zellmembranen deuten konnte. Häufig war ein Rest des Zellinhalts in ihnen zurückgeblieben.

Die runden oder elliptischen Kerne der Zellen standen bei allen drei von mir geprüften Repräsentanten dieser Thierclasse in Relation zur Grösse der Zelle. Durch carminsaures Ammoniak färben sie sich schön rosa. Im Innern des Kerns erkannte ich reglmässig ein glänzendes, solides Kernkörperchen. Ausser einer hie und da etwas stärkeren Granulirung des Kerninhalts bot der letztere keine weitere Structur dar. Bei Anodonta und Unio sah ich häufig zwei Kerne in einer Zelle. Räthselhaft blieb mir ein in Fig. 14 gezeichnetes Verhalten, wo ich in einem Fortsatz nahe der Zelle auf einen kleinen, von Carmin roth tingirten Kern stiess; 
man könnte somit den Fortsatz als Zelle deuten, welche durch eine "Commissur" mit der grösseren zusammenhing.

Während die Ganglienzellen der Elatobranchier theils ihrer geringen Grösse, theils des starken Pigmentgehaltes wegen nur schwer eine "fibrilläre Structur" erkennen lassen, findet man dagegen desto häufiger in Fibrillenbtindel zerfallende Zellfortsätze.

\section{Die Nervenstämme und Nervenfasern der Elatobranchien.}

Die Nervenstämme der von mir untersuchten Muscheln zeichnen sich aus durch ein sehr lockeres zartes Neurilemm. Während das Neurilemm der Gasteropoden und Würmer eben seiner Straffheit wegen der Isolirung der Nervenfasern grosse Hindernisse bereitet, weil die Secundärscheiden ihrer Dicke wegen fest mit dem primären Neurilemmarohr zusammenhängen, könnte man von dem Neurilemm der Muscheln das Gegentheil behaupten. Man erkennt hier eben ibrer Zartheit wegen nur schwierig an optischen Längsschnitten die Secundärscheiden, trifft dagegen hier viel häufiger isolirte Fibrillenbündel als bei Gasteropoden und Würmern.

An grösseren Nervenstämmen, etwa von der Dicke des Mantelnerven, wird man nicht lange darïber in Zweifel bleiben können, ob die Nerventämme der Elatobranchier einen anderen Bau zeigen, als ich ihn bisher bei den von mir untersuchten Wirbellosen gefunden. Ein guter Querschnitt (wie ihn Figur 20 vom Mantelnerven von Mytilus edulis darstellt) liefert alsbald den Nachweis, dass das Lumen des Nervenstammes durch ein allerdings sehr zartes bindegewebiges Netzwerk in eine Unzahl Fächer abgetheilt ist. In der unteren Hälfte der Figur ist der nervöse körnig-fibrilläre Inhalt in einer schmalen Randzone in den Maschen des Netzwerks haften geblieben; hier ist es schwer die bindegewebigen Septa zu erkennen. Oben dagegen, wo die Maschen leer sind, erkennt man deutlich radiär vom primären Neurilemm ausstrahlende Secundärscheiden. Inwieweit die scheinbar grosse Differenz in der Grösse der abgetheilten Fächer durch eine schrumpfende Wirkung des Reagens verschuldet ist, mag dahingestellt bleiben.

Auf der Schnittfäche erkennt man ferner mehrere spindelförmige Zellen, die deutlich in den Maschen des Netzwerks 
liegen und somit wohl als Ganglienzellen angesprochen werden dürfen.

Die Figur 22, in welcher eine Verästelung des Mantelnerven von Mytilus edulis gezeichnet ist, weist eine grössere Anzahl sogenanter interponirter Ganglienzellen auf.' Beide Figuren sind nach Präparaten Flemming's von mir gezeichnet.

Zupfpräparate, welche mit Ammon. bichrom. (0,05\%) und carminsaurem Ammoniak behandelt waren, lieferten mir deutliche „fibrilläre" Bilder; Figur 17 stellt ein stärkeres, aus einem Nervenstamı isolirtes Fibrillenbündel dar, welches im Innern aber wiederum die Conture von Secundärscheiden erkennen lässt. In Figur 18 strahlt die nervöse Inhaltsmasse büschelförmig in Fibrillen aus. Ob alle im Lumen schwach sichtbaren Zellen nervöser oder bindegewebiger Art seien, liess sich an diesen Präparaten nicht entscheiden. Ein grosser Theil der roth gefärbten Kerne gehört jedenfalls dem Neurilemm an, welches ferner noch eine fettïhnliche, in Körnchenreihen gruppirte, glänzende Substanz enthält. Sogenannte Schleimzellen wie ich sie im Neurilemm der Gasteropoden beschrieben, enthält die Nervenscheide der Muscheln nicht. - Sehr viel klarere Bilder erhielt ich mit der Osmiumsäure, welche mir höchst eigenthïmliche Structurbestandtheile vor Augen fülıte. Nervenstämme sowohl wie Nervenfasern zeigten schon bei schwacher Vergrösserung ein anffallend grob granulirtes Aussehen. Bei stärkerer Vergrösserung erwies sich als die Ursache der Granulirung eine Unzahl tief schwarz gefärbter Körner oder Tröpfchen. Der bei weitem grössere Theil dieser eigenthümlichen, von Osmium tingirten Substanz lag im Innern höchst merkwürdiger Gebilde. Die Nervenstämme und -Fasern zeigten nämlich im Innern zwischen den nervösen Fibrillen zahlreiche langgestreckte, spindelförmige, meist bipolare, Zellen. In diesen Zellen, meist in der Nähe der Kerne, lagen reihenweise die schwarz gefärbten "Tropfen" in sehr wechselnder Anzahl und Grösse. (Vergl. Fig. 21 und 23.) Im isolirten Zustande erschienen die Zellen bei starker Vergrösserung als kernführende Fibrillenbündel; die Fortsätze splitterten in der Regel in einen Büschel von Fibrillen auf. Neben der bipolaren Form war die vielstrahlige vertreten, die man anfangs kaum für Nervenzellen hätte halten mögen, wenn nicht auch hier eine körnige, interfibrilläre Substanz für ihre nervöse Natur gesprochen bätte. 
Das Vorkommen solcher langgestreckten, zahlreich verästelten, und wie wir wohl annehmen dürfen, eben mittelst ihrer Fortsätze in die leitende nervöse Substanz eingeschalteten Zellen ist von mir an zablreichen Osmiumsäurepräparaten von Anodonta und Unio bestätigt worden, und stehe ich nicht an, in dem Vorkommen dieser Zellen eine ganz characteristische Eigenthïmlichkeit der Nerven der Elatobranchier zu sehen. Denn die bei Gasteropoden wie Würmern in viel geringerer Anzahl vorkommenden, sogenannten in terponirten Nerven-Zellen sind von den eben geschilderten durohaus verschieden. Somit kommt in den Nervenstämmen der Elatobranchier eine ganz specifische Form von Nervenzellen vor, die ich nie in den nervösen Centren oder in peripherischen Verzweigungen gesehen. Was diese Zelle aber besonders interessant macht, das ist das Auftreten jener körnigen, von Osmium geschwärzten myelin-äh nlichen Substanz. Die letztere kommt nun auch diffus zwischen und innerhalb der Fibrillenbündel vor (vergl. Fig. 24), nur ist sie hier mehr feinkörnig, nicht an Tropfen erinnernd, wie in den Zellkörpern.

Ich erwähnte bereits oben in dem Abschnitte über die Gastero poden gelegentlich der Besprechung der verschiedenen Uebergangsarten centraler Zellfortsätze in periphere Nervenfasern, dass mir bei Elatobranchiern wiederholt der Nachweis eines sogenannten indirecten Uebergangs mit Einschaltung kleinerer Ganglienzellen geglückt ist. Um Wiederholungen zu vermeiden, beschränke ich mich daher hier auf eine Erklärung meiner Abbildung in Fig. 18. Eine grosse multipolare Ganglienzelle aus der Randzone des unteren Ganglions von Anodonta hängt durch ihre Fortsätze mit zwei kleineren multipolaren Ganglienzellen zusammen. Erst die Ausläufer dieser letzteren lösen sich in ein Netzwerk körnig-fibrillärer Substanz auf, wie sie im Centrum des Ganglions vorhanden ist. Aus dieser letzteren entspringen dann die verschiedenen, einen Nervenstamm constituirenden Fibrillenbündel, resp. Nervenfasern.

\section{Würmer.}

Untersuchungsmethoden.

Als Repräsentanten dieser Classe der Wirbellosen wählte ich Hirndo medicinalis und Lumbricus agricola zur Untersu- 
chung. Dass ich bei meinen Untersuchungen tiber die feineren Structurverbältnisse der Nervenfasern und Ganglienzellen von Hirudo medic. zu zum Theil anderen Resultaten als Hermann gekommen bin, und insbesondere rücksichtlich der Fibrillarität mit den anderen Wirbellosen so übereinstimmende Bilder erhalten habe, glaube ich der Wahl der bei Gasteropoden und Muscheln erprobten Reagenzien zu danken. Aber gerade bei Hirudo habe ich auch mit grossem Nutzen die Untersuchung im frischen $\mathrm{Zu}$ stande, im Blate des Thieres und in Jodserum vorgenommen. Bei der Wahl der Conservationsreagenzien nusste ich vor Allem darauf Bedacht nehmen, auf das der Zerzupfung so sehr widerstehende straffe Neurilemm, welches die Ganglien, das Bauchmark und die Nervenstämme einhüllt, guinstig einzuwirken. Mit Vortheil legte ich zu diesem Zweck die Präparate mehrere Secunden lang in concentrirte Essigsäure, oder liess dieselben lüngere Zeit in Schwefelsäure liegen. Zur Härtung bediente ich mich wieder dünner Chromammonlösungen. Die Nervenfasern und Ganglienzellen von Hirudo zeichnen sich gegenüber dem straff-widerspänstigen Neurilemm durch grosse Zartheit und Fragilität aus.

\section{Gangli enze 11 e.}

Die Grundform der Ganglienzellen aus den Schlund-, Bauch- und Schwanganglien von Hirudo ist keulen-oder spindelförmig; auch hier überwiegt bei Weitem der unipolare Habitus; insbesondere sind auch hier die grossen, an der Peripherie der Ganglien gelagerten Zellen unipolar. Multipolare Zeilen sah ich nur sehr selten, und immer waren es kleinere, welche diese Form hatten; häufiger begegnete ich bipolaren und diesen wieder häufiger in Gestalt der sogen. interponirten Zellen im Verlaufe der Nervenstämme als in den Centren. Hinsichtlich der Grössenverhältnisse stimmen meine Maasse mit denen Hermann's iberein.

Im frischen Zupfpräparat fand ich, wie dies anch von Hermann beschrieben ist, regelmässig der Zelle eine feinkörnig-fibrilläre Masse anhaften; die Fibrillen zeigten häufig feinste Varicositäten. $\mathrm{Ob}$ dieselbe aber unzweifelhaft nervöser oder, wie Hermann glaubt, bindegewebiger Natur sei, davon konnte ich mir keinc Gewissheit verschaffen. Die Varicositäten sprechen wohl mehr für eine Identität mit der im Centrum der Ganglien vorhandenen 
fibrillären Substanz, welehe auch hier augenseheinlich durch den allmäligen fibrillären Zerfall der Zellfortsätze gebildet wird. Ich erhielt oft an guten Zupfpräparaten bierfür ganz thberzengende Situsbilder.

An frischen, gut isolirten Zellen war eine Membran mit Bestimmtheit nicht nachzuweisen. Dagegen gluckte es mir an erhärteten Präparaten wiederholt, eine den etwas geschrumpften Zellkörper schalig umgebende, mit kleinsten Kernen versehene Hüllensubstanz zu constatiren, deren Contoure oft ganz scharf auf den Zellfortsatz sich weitererstreckten (Fig. 30). Anfangs hielt ich diese Hïlle ftir Reste des bindegewebigen Fachwerks, welches im Ganglion die grösseren Zellen einschliesst; ich sollte aber bald sicheren Aufschluss tiber die Natur dieser Substanz erhalten. Die in Fig. 28 abgebildete Zelle nämlich zeigt bei a eine Läsion; der Zellinhalt ist hier augenscheinlich durch den Fortsatz herausgerissen. Die leere, röhrig verzweigte Scheide des Fortsatzes, welche, wie ich wohl annehmen darf, auch hier den Zellkörper als „Mem-

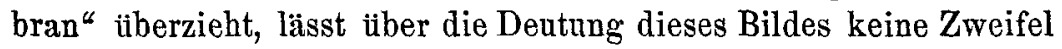
bestehen. Später gelang es mir denn auch wiederholt in frisehen, in Jodserum zerzupften Präparaten auf leere, im Gesichtsfeld herumschwimmende Zellhiillen zu stossen; häufig war noch ein Rest des körnig-fibrillären Zellinhalts an der Rissstelle im Austreten zu beobachten. Die ganz ähnliche Figur 29 ist nach einem in Ammonium bichrom. erbärteten Präparat gezeichnet. Hermann gegenüber muss ich betonen, dass es in derartigen Fällen absolut keiner "Phantasie" oder "Kiinstelei" bedurfte, um sich von der Existenz dieser „Membranen" zu tuberzeugen.

Die Controverse uber die Zellmembran der Ganglienzellen Wirbelloser ist so alt, wie die Untersuchung der Nervenelemente dieser Thiere. Leydig erklärt sich mit aller Entschiedenheit gegen eine solche; er demonstrirte zuerst das bindegewebige Fachwerk im Ganglion und sah an isolirten Zellen nur eine erhärtete Rindensubstanz, welche den Eindruck einer Membran hervorrufen könnte. Waldeyer schliesst sich Leydig an; dagegen haben Valentin, Faivre, Owsjannikow, Walter und Solbrig, allerdings nur in wenigen Fällen, eine Membran beobachtet. Hermann schreibt merkwürdigerweise der "sympathischen Ganglienzelle von Hirudo eine Membran zu im Gegensatz zur centralen. Hermann bielt sich wegen dieses und anderer 
abweichender Befunde ${ }^{1}$ ) für berechtigt, das "sympathische ${ }^{\text {" dem }}$ cerebrospinalen oder schlechthin peripherischen Nervensystem Wirbelloser scharf gegenüberzustellen; ich verweise auf das bei $\mathrm{Ga}$ steropoden hieruber Gesagte. Von Hirudo medicinalis gelang es mir leider nicht, brauchbare Präparate der "sympathischen" Darmnerven zu erhalten.

Die Ganglienzelle von Hirudo erschien mir sowohl bei der Untersuchnng im frischen Zustande, als nach Anwendung von Reagenzien fibrillär; die Fortsätze waren gleichfalls fibrillär; wiederholt sah ich Fortsätze, welche in Btischel von Fibrillen bei der Präparation zerfallen waren. Mit Rïcksicht anf diesen Befund, der mit den friber bei Gasteropoden und Muscheln gemachten Beobachtungen iiber den fibrillären Bau so völlig ïbereinstimmt, halte ich mich für berechtigt, die zuerst von Fle ischla ) bei Ganglienzellen ans dem Ganglion Gasseri von Rana und dann von Hermann bei Nervenzellen von Hirudo gesehene globuläre" und ,interglobuläre" Substanz für Artefacte der Borsäure $z \mathfrak{u}$ halten. Da ich mich bereits an anderei Stelle ${ }^{3}$ ) über diese Fleischl'sche „Entdeckung" geäussert und meine Ansicht über die Bedeutung der Borsäurebilder vertreten habe, hielt ich es nicht für nöthig, auch die Ganglienzellen von Hirudo in ihrem Verhalten zu dieser Säure zu prüfen.

Der Kern der Ganglienzelle von Hirudo war an frischen Präparaten rund und doppelt-contourirt, sein Aussehen crystallklar; an solchen frischen Kernen habe ich keine weitere Structur gesehen; nach der Behandlung mit Chromsalzen und Osmiumsäure erschienen im Kern verschieden zahlreiche Körnchen; indessen sah ich bei dieser Behandlung keine Kernnetze.

Die Grösse des Kernes fand ich stets proportional der Zellgrösse; wiederholte Messungen veranlassen mich dies Hermann gegenüber besonders zu betonen. Meine Kernmaasse schwankten zwischen 0,015 und $0,002 \mathrm{~mm}$. Kern- nnd Kernkörperfäden habe ich bei Hirado nie gesehen, und befinde ich mich in dieser Beziehung im Einklang mit Leydig, Will, Bruch, Buchholz, Waldeyer, Walter und Hermann.

1) Vgl. oben.

2) Fleischl: „Ueber die Wirkung von Borsäure auf frische Ganglienzellen". Wiener Sitzungsber. Bd. LXI II. 1870.

3) Archiv f. Anat. u. Entwicklungsgesch. 1878. Heft IV. 
Das Kernkörperchen von Hirudo ist nach den Untersuchungen von Hermann kein frei im Kern suspendirtes Körperchen; es stellt hier vielmehr eine linsenförmige Verdickung der Innenwand der Kernmembran dar. Diese auffallenden Angaben Hermann's veranlassten mich die Kernkörper von Hirudo näher zu prïfen. In der grossen Mehrzahl der Fälle liegt dasselbe nun excentrisch, und zwar der Innenwand der Kernmembran an; doch stellt dasselbe ein völlig abgegrenztes Körperchen dar. In allen Fällen, wo ich glaubte anfangs die Beobachtung Hermann's bestätigen zu können, überzeugte ich mich nachträglich, dass der innere Contour der Kernmembran neben dem Kernkörperchen vorbeilief. Hermann giebt nämlich an, dass das Kernkörperchen, im Profil gesehen, sich meist so darstelle, als bilde die innere Kernwand eine buckelförmige Prominenz ins Innere des Kerns (vgl. Fig. 34 a u. b). Indessen habe ich dies nie bestätigen können, insofern immer ein schmaler Zwischenraum zwischen Kernkörper und Kernmembran zu constatiren war. Häufig sah ich dagegen halbmondförmige Einkerbungen, oft mehrere an einem Kern, an denen aber immer beide Contoure der Membran theilnahmen (vgl. Fig. 34c). Auch beobachtete ich am Kernkörper nicht selten eine buckelartige Auflagerung, so dass das Ganze eine hutförmige Gestalt annahm.

Den Ganglienzellen von Hirudo und wie ich gleich hinzufügen will, auch von Lumbricus agricola fehlt das circumscript an der Abgangsstelle des Hauptfortsatzes gelagerte Pigment, wie es bei Gasteropoden und Muscheln so constant vorkommt. Häufig sah ich an Ganglienzellen von Hirudo ein sehr wechselndes Verhalten der Zellsubstanz zur Carminfärbung; die Färbung war oft in concentrisch den Kern umkreisenden Zonen verschieden intensiv ausgefallen, nicht selten war das Centrum der Zelle und die Peripherie dunkel tingirt, während eine scharf begrenzte Zwischenzone heller geblieben war.

\section{Nervenstämme und Nervenfasern.}

Der Bau der Nervenfasern von Hirudo ist zuerst von Hermann griindlich erforscht. Hermann entdeckte, wie bereits oben erwähnt wurde, den gefächerten Bau im Innern der primären Neurilemmascheide. Ich konnte schon hänfig an guten optischen 
Längsschnitten diesen Bau erkennen. (Figuren 31, 32 u. 33.) Die Figur 31 stellt ein Commissurenpaar dar, welches zwei Bauchganglien untereinander verbindet; in der Mitte ist der "intermediäre" Nerv Faivres, welcher häufig durch kurze Anastosmosen mit den Commissuren sich in Verbindung setzt, welche wie schon von Leydig hervorgehoben wird, immer einseitig auftreten. Ich betone ausdricklich, dass sowohl Commiss uren wie periphere Nerven diese Secundärscheiden besitzen; die Figur 33 stellt einen peripheren Nerv dar, welcher ein isolirtes Fibrillenbiundel abgiebt; das letztere, welches bei a nackt aus seiner Scheide heraustritt, kann mit Recht als das Aequivalent einer Nerven-,Faser“ im Sinne der Wirbelthierfaser aufgefasst werden.

Walter beschreibt zwischen Fibrillenbündeln und Neurilemm bei Hirudo eine "durch Druck leicht versebiebbare", feinkörnige Masse. Ich muss dazu bemerken, dass ich wiederholt ähnliche Bilder, wie Walter sie in seiner Fig. $\mathrm{V}$ a anf Taf. I abbildet, bekommen habe; doch gewann ich die Ueberzengnng; dass Walter leere Scheidefächer für „Fasern", ihren weggedrückten körnigfibrillären Inhalt dagegen für jene die Nervenfasern angeblich umgebende Substanz gehalten hat. Es gelang mir wiederholt durch Druck solche Bilder künstlich hervorzurufen. Walter will diese feinkörnige Substanz nun ferner nur in den Commissuren gesehen haben; ich wiederbole, dass ich nie einen Unterschied in der Structur der Commissuren und Nervenstämme beobachtet habe; höchstens wäre zu bemerken, dass, wie Hermann es hervorhebt, die Commissuren sehr verschieden dicke Secundärfächer besitzen, während diese letzteren bei den übrigen Nerven mehr übereinstimmend breit gefunden werden. Leydig's Angaben über einen verschiedenen Bau der Commissuren und Nervenstämme sind somit durch den von Hermann für beide gebrachten Nachweis der Secundärfächer widerlegt.

Das Neurilemm der Nerven von Hirudo besitzt nur spärliche Kerne, sowie eine häufig in Körnchenreihen gruppirte glänzende, fettähnliche Substanz. "Inraginationen" des Neurilemm, wie Walter sie sah, habe ich nie beobachtet, auch erwähnt Hermann diese nicht. Eine häufig von mir gesehene Einschnürung möchte ich für ein bei der Präparation entstandenes Kunstproduct halten.

An feineren Verzweigungen der Nerven von Hirudo sah ich 
oft schon bei der Untersuchung im frischen Zustande fibrilläre Anfsplitterungen. Auch Hermann sieht die "Fibrille“ als letzte Structureinheit in den „cerebrospinalen" Nerven von Hirudo an, wie er auch jene abgefächerten Bündel in den Nervenstämmen als differenzirte Nervenfasern betrachtet. Aber auffallender Weise repräsentirt die sympathische Faser von Hirudo nach Hermann kein solches Fibrillenbündel: die sympathische Faser ist nach Hermann homogen oder fein granulirt. Her. man $n$ fügt dieser Bemerkung die Worte hinzu: ,auch sei ja eine fibrilläre Structur mit dem nachweisbaren Ursprunge der sympathischen Fasern aus dem Ganglienkörper nicht recht vereinbar" (pag. 56). Hermann hat kurz zuvor den häufig von ihm im Darm von Hirudo beobachteten Ursprung sympathischer Fasern aus Ganglienzellen angeführt. Ich muss daher die oben citirte, nur schwer verständliche Notiz Hermanns so deuten, als könne Hermann sich den Ursprung einer "fibrillären" Faser aus der "globulären" Ganglienzelle nicht recht vorstellen. Leider besitze ich keine Präparate der Darmnerven von Hirudo; mit Riicksicht auf die gTosse Uebereinstimmung, welche ich bei Gaste ro poden zwischen dem sympathischen und cerebro-spinalen System gefunden habe und mit Ritcksicht auf meine oben erörtete Ansicht über die ,globuläre" und ,interglobuläre Substanz muss ich die Hermann'schen Angaben in Zweifel ziehen; höchstens könnte die Erkennung der Fibrille in den Darmnerven weniger leicht gelingen als anderswo, woran ja auch die verschiedenen Reagenzień schuld sein könnten.

In den peripheren Nerven von Hirudo begegnete ich sehr häufig den auch von Hermann beschriebenen, sogenannten , in terponirten" Ganglienzellen, die hier jedoch weit spärlicher vorkommen als bei Gasteropoden und Muscheln; überhaupt habe ich dieselben immer nur in unmittelbarer Nähe abgehender Nervenzweige an den Theilungsstellen beobachten können.

Nervenfaser und Ganglienzelle von Lumbricus agricola.

Die Structur der Ganglienzelle von Lumbricus stimmt so völlig mit derjenigen von Hirudo überein, dass ich der obigen Darstellung nichts hinzuzufügen habe. Nur fand ich das Kernkörperchen in der Regel im Centrum des Kerns, und nicht wie bei $\mathrm{Hi}$ rudo an der Innenseite der Kernmembran gelegen. 
Nach Leydig (a. a. O. pag. 154) begegnet man bei Lumbricinen keiner so scharf ausgeprägten Nervenprimitivfaser wie bei Hirudo; der Inhalt der Nerven von Lumbric as besteht nach Leydig aus einer Mischung feiner Fäserchen und einer Punktsubstanz. Auch Waldeyer erklärt den Inhalt der Seitennerven von Lumbricus für büllenlose Axencylinder. Da Waldeyer die Secundärfächer im Innern nicht bekannt waren, fällt diese Auffassung Waldeyers somit mit der von Leydig zusammen. Waldeyers Angabe glaubte ich anfangs auf Grund frisch untersuchter Präparate bestätigen zu muissen. Indessen zeigten die Seitennerven unter Anwendung verschiedener Reagenzien sebr scharfe Secundärscheiden. Dass sie an frischen Präparaten nicht zu sehen, liegt wohl an der grösseren Zartheit, welche alle nervösen Structurelemente von Lumbrieus gegenüber denen von $\mathrm{Hirudo}$ auszeichnet.

An Rissstellen, wo der nervöse Inhalt blischelförmig austrat, sowie auch an guten optischen Längsschnittshildern frischer Präparate uiberzengte ich mich von der schon von Leydig hervorgehobenen stärkeren Anhäufung der körnigen, interfibrillären Punktsubstanz.

Die an der Rückenseite des Bauchmarks gelegenen, von Leydig entdeckten, riesigen, dunkelrandigen Fasern mit centralem Fibrillenbiindel habe ich sowohl an frischen Zupfpräparaten als auch nach vorheriger Osmiumsäureeinwirkung dargestellt. Ihr Auffinden wird einmal sehr erschwert durch die Straffheit des uberhaupt der Untersuchung nervöser Strueturtheile von Lumbricus hinderlichen Neurilemms. Letzteres ist nämlich reich mit Muskelfasern ausgerüstet. Aın besten gelang mir noch das Zerzupfen an ganz frischen Präparaten, die wenige Secunden in concentrirter Essigsäure gelegen hatten. Die durch Osmium sich schwarz färbende breite Myelinscheide jener Fasern ist äusserst fragil und in Zupfpräparaten immer nur auf kurze Strecken zu erhalten. Dabei fällt das centrale Fibrillenbündel sehr leicht aus der Scheide heraus; wenigstens begegnet man mehr Scheidenstiicken, die leer sind, als solchen, wo das centrale Bündel erhalten. Schon Leydig macht darauf aufmerksam, dass diese Fasern häufig leeren Blutgefässen täuschend ähneln; indessen die abweichende Structur der Gefässwand bewahrt uns leicht vor diesem Irrthum. 


\section{Schlussbemerkungen.}

Im Folgenden recapitulire ich kurz die wichtigsten Punkte meiner Untersuchungen.

I. Im Nervensystem der von mir untersuchten Gasteropoden, Muscheln und Würmer konnte ich uberall als letzte Structureinheit die Primitiv-,Fibrille“ zur Darstellang bringen. - Ich babe die Fibrille in Nervenzellen wie - Fasern sowohl bei der Untersuchung im frischen Zustande, als mit Hülfe der verschiedensten Reagenzien gesehen. Die Untersuchung im frischen Zustande scheitert indessen in vielen Fällen an ungünstigen Lichtbrechungsverbältnissen, welche, wie ich anzunehmen geneigt bin, durch die Gegenwart einer die Fibrillen umgebenden Substanz bedingt werden. Diese Substanz ist im Leben zäh-flüssig; durch Reagenzien gerinnt sie zu den gewöhnlich so genannten interfibrillären Körnern.

II. Der von Hermann für die Nervenstämme und Commissuren von Hirudo entdeckte, abgefächerte Bau der Nearilemmascheiden gilt nach meinen Untersuchungen in derselben Weise für die Nervenstïmme und Commissuren der Gasteropoden and Elatobranchiaten. Die sympathischen Nerven der Gasteropoden scheinen hiervon eine Aus a ahme zu machen. Somit besitzen diese Repräsentanten aus drei Classen der Wirbellosen keine scharf differenzirten Nervenfasern im Sinne der cerebro-spinalen, markhaltigen Wirbelthier-Faser; doch erlaubt der eigenthümlich gefächerte Bau des Neurilemms in jedem der Art abgeschlossenen Fibrillenbündel das Aequivalent der Nerven-Faser zu erblicken.

III. Die centralen Zellfortsätze sollte man nicht schlechthin Nervenfaser oder Nervenfibrille nennen. Sie lösen sich durch fortgesetzte Theilung in die körnig-fibrilläre netzförmigverzweigte Centralsubstanz anf, aus dieser letzteren erst bilden sich direct Nervenfasern. Bei den Elatobranchiaten habe ich wiederholt einen anderen Modus des sogenannten indirecten Uebergangs beobachtet. Kleinere multipolare Ganglienzellen sind in die Leitungsbahn $\mathrm{z} w$ ischen die grösseren Zellen und die nervöse, anastomotische Centralsubstanz einge- 
schaltet. Auch sah ich bei Gasteropoden häufig intercellulare Commissuren. Der directe Uebergang eines grossen Zellfortsatzes in eine zur Peripherie verlaufende Nervenfaser ist bisher durch kein einziges unanfechtbares Beispiel sichergestellt.

IV. Der von mir bei Helix und Arion untersuchte $\mathrm{N}$. sympathicus ist gegenüber dem cerebro-spinalen System ausgezeichnet durch einen grossen Zellenreichthum, sowie durch den Mangel der "Seeundärscheiden"; hinsichtlich der Fibrillaritat bestehen keine Differenzen.

V. Im Hautmuskelschlauch und $\mathrm{F}$ ühler von Helix kommt eine von Flemming entdeckte, ganz characteristische Form von Ganglienzellen vor. Diese Zellen sind neben ihrer eingenthümlichen Gestalt, Lage und Verbindung ausgezeichet durch eine von mir beobachtete, specifische, interfibrilläre Sub$\operatorname{stanz}$, welche völlig analog der von Flemming in den Endverzweigungen des Mantelnerven von Mytilus entdeckten, ,granulirten Subtanz" zu sein scheint.

VI. In den Nervenstämmen und Nervenfasern der Elatobranchiaten kommt ebenfalls eine höchsteigenthümliche, durch 0smium schwarz sich färbende, myelinähnliche $S$ ubstanz sowohl interfibrillär als intercellulär vor.

VII. Die Ganglienzellen der Elatobranchiaten und Wiirmer, sowie die sympathischen Zellen der Gasteropoden besitzen unzweifelhaft eine auf den Fortsatz übergehende structurlose Membran.

\section{Erklärung der Abbildungen.}

Sämmtliche Bilder sind mit mittelstarken Linsen (Zeiss Immersion F) gezeichnet; stärkere Systeme wurden absichtlich vermieden, um Täuschungen durch Beugungserscheinungen zu entgehen. Die Figuren 11, 20 und 22 sind nach Präparaten des Herrn Professor Flemming gezeichnet.

\section{Tafel $\mathrm{V}$.}

Fig. 1. Riesige centrale Ganglienzelle aus dem Ganglion infraoesophageum von Helix pomatia; zwei Fortsätze entspringen von demselben Pol isolirt. Das Pigment erstreckt sich in die 
Die fibrilläre Structur der Nervenelemente bei Wirbellosen.

Fortsätze hinein. Ammonium bichrom. 0,05 pCt.; carmins. Ammoniak.

Fig. 2. Centraler Zellfortsatz; bei a hebt sich die sehr scharfe structurlose Membran ab; bei $b$ in Fibrillen sich auflösend. Behandlung wie oben.

Fig. 3. Kernfortsatz von Helix pomatia aus dem Ganglion infraoesophag. In Ammonium bichromic. frisch untersucht. Nachherige Tinction mit picrocarmins. Natron.

Fig. 4. Desgl. Osmiumsäure 0,1 pCt.; carmins. Ammoniak.

Fig. 5. Desgl. Ganglienzelle von Arion ater aus dem Ganglion infraoesophagum. Osmium 0,1 pCt.; carmins. Ammon.

Fig. 6. Desgl. Aus dem Gangl. supra-oesophag. von Helix nemorosa. Osmium 0,1 pCt.

Fig. 7. Isolirter Kern ebendaher. In den Figuren 5 und 7 ist der Kerninhalt im Ausfliessen begriffen. (A rtefacte.)

Fig. 8. Präparat des Darmnervengeflechts eines jungen Exemplars von Helix pomatia. Concentr. Essigsäure 3 Min. carmins. Ammoniak.

Fig. 9. Schleimzelle aus dem Neurilemm von Helix pomatia. Ammon. bichromic. 0,1 pCt.

Fig. 10. Mittelstarker Nervenstamm von Arion ater. Kernhaltiges Neurilemm mit fettig glänzender Körnersulstanz; Contoure der Secundärscheiden. Der fibrilläre Inhalt tritt büschelförmig aus. Ammon. bichr. 0,1 pCt.; Schwefelsäure 0,5 pCt.; carmins. Ammoniak.

Fig. 11. Querschnitt des Fühlernervenstammes von Helix pomatia. Neurilemmatisches Fachwerk mit Kernen. In den leeren Maschen vereinzelte zurückgebliebene Ganglienzellen. Kali bichr.

Fig. 12. Centrale Ganglienzelle von Unio pictorum aus dem unteren Ganglien-Paar. Characteristisches $\mathrm{Pigment}$ mit grösseren fettig-glänzenden Tropfen. Ammon. bichromic. 0,1 pCt.; carmins. Ammoniak.

Fig. 13. Desgl. Grosse doppelt-contourirte Tropfen an Stelle des Pigments. Behandlung wie oben.

Fig. 14. Multipolare Ganglienzelle von Anodonta; Behandlg. wie oben.

Fig. 15. Unipolare Zelle ebendaher. Das sehr reichliche Pigment ist durch Osmium leicht gefärbt. Osmium $0,1 \mathrm{pCt}$.

Fig. 16. Leere Zell-Membran von Mytilus edulis. Aussen haftet körnigfibrilläre Inhaltsmasse an. Friches Zupfpräparat.

Fig. 17. Grösseres „primäres" (Waldeyer) Fibrillenbündel mit Secundärbündeln im Innern, isolirt aus einem grösseren Nervenstamm von Anodonta. Ammon. bichr.; carmins. Ammoniak.

Fig. 18. Kleiner Nervenstamm von Unio. Ammon. bichr.; carmins. Ammoniak. 
Fig. 19. Grosse multipolare Ganglienzelle von Anodonta. Indirecter Uebergang der Fortsätze durch das Bindeglied kleinerer, multipolarer Zellen in körnig-fibrilläre Centralsubstanz. Ammon. bichr. 0,1 pCt.; carmins. Ammoniak.

\section{Tafel VI.}

Fig. 20. Querschnitt des Mantelnerven von Mytilus. Secundärscheiden. Vereinzelte Ganglienzellen in den Maschen des neurilemmatischen Fachwerks. Rechts ist nervöser Inhalt erhalten.

Fig. 21. Eigenthümliche myelinähnliche Substanz in einem Nerven von Anodonta. Osmium $0,1 \mathrm{pCt}$.

Fig. 22. Mantelnervverzweigung von Mytilus. Zahlreiche interponirte Ganglienzellen.

Fig. 23. Die myelinähnliche, intracellulare Substanz in einer aus dem Präparat 21 isolirten spindelförmigen Nervenzelle.

Fig. 24. Dieselbe Substanz als interfibrilläre in Fibrillenbündel. Ebenfalls aus Präparat 21 isolirt.

Fig. 25. Aus dem Fühlerknopf von Helix pomatia. Nervenzellen$z$ u g II. Ordnung aus dem gangliösen Lager (g. L.) kommend, die Hautmuskelschicht (h. m.) durchsetzend und in Fibrillen bündeln zwischen je 2 Epithelzellen aufsteigend; gs = granulirte Substanz; b. z. = Becherzellen.

Fig. 26. Ebendaher. Goldpräparat. N. z. = Nervenzellenzug; b. subepitheliale Hautmuskelschnitt; c. Cuticularsaum; b. und c. stark von Gold geschwärzt.

Fig. 27. Characteristische, körnige Substanz an den eigenthümlichen Ganglienzellen im Fühlerraum und Fühlerknopf. Die „, a akten" Fibrillen gehen an's Epitlhel. aa. isolirte Nervenzellen in dem subepithelialen Stratum. GoIdpräparat.

Fig. 28. Ganglienzelle aus dem Bauchmark von Hirudo medic.; bei $a$ ist der nervöse Inhalt durch einen Zupfinsult herausgerissen; $m$ leere Membran auf den Fortsatz übergehend. Frisches Präparat. Jodserum.

Fig. 29. Zellenmembran ebendaher. Der nervöse Inbalt theilweise ausgetreten. A mmon. bichr. 0.1 pCt.

Fig. 30. Ganglienzelle von Hirndo mit Zellmembran und aussen anhaftender körnig-fibrillärer Substanz. Frisch untersucht im Blute des Thieres.

Fig. 31. Commissuren-Paar des Bauchstrangs von Hirudo medicinalis mit dem "intermediären" Faivre'schen Nerven; bei a eine Anastomose dieses letzteren Nerven mit einer Commissur. Ammon. bichromic. 0,02 pCt.; Schwefelsäure 0,5 pCt.; Ammoniak.

Fig. 32. Seitennervenpaar von Lumbricus agricola; in der Mitte ein leeres Blutgefäss. Ammon. bichromic. 0,02 pCt.; carmins. A mmoniak. 
Fig. 33. Nervenfaserbündel von Hirudo medicinalis; bei a ein isolirtes Fibrillenbündel abgebend. Frisch im Blute des Thieres untersucht.

Fig. 34. Kernkörper von Hirudo. a nach Hermann; b hutförmiges Kernkörperchen; der Contour der inneren Kernmembran hört nicht auf; c Einkerbung der Kernmembran; nach frischen Präparaten gezeichnet.

\title{
Ueber die Veränderungen des serösen Epithels am blossgelegten Froschmesenterium.
}

\author{
Von
}

Dr. med. Miohnual Altmann,

Assistenten am pathologischen Institut in Giessen.

Hierzu 3 Holzschnitte.

Betrachtet man an dem blossgelegten Mesenterium des Frosches die anf der Oberfläcle desselben sich abspielenden Vorgänge, so sieht man, dass die Zellen des serösen Epithels mannigfache Veränderungen eingehen. Da dieselben am deutlichsten und leichtesten an Querschnittsbildern zu verfolgen sind, so nehmen wir zunächst eine Falte des Mesenterium ins Auge, die mit oder ohne Absicht leicht zu erhalten ist.

Während die Zellen des serösen Epithels im normalen lebenden Zustande so platte Gebilde vorstellen, dass sie auf dem Querschnitt nur als lineare Begrenzung des Gewebes erscheinen und kaum als besondere Gebilde wahrzunehmen sind, sieht man bald nach der Blosslegung des Mesenterium Anschwellungen des serösen Epithels auftreten, die wir ihrer Verschiedenheit wegen in zwei Gruppen sondern missen, in tribe und homogene.

Die trüben Schwellungen erscheinen bald nach der Bloss. legung des Mesenterium zunächst als lange, spindelförmige Figuren, deren eine Begrenzung, die vom Gewebe des Mesenterium gebildete, 